Check for updates

Cite this: RSC Adv., 2018, 8, 18093

\section{Role of reactant concentration and identity of added cation in controlling emission from post- synthetically modified terbium incorporated zinc sulfide nanoparticles: an avenue for the detection of lead(II) cations $\uparrow$}

\begin{abstract}
Saoni Rudra, Gouranga H. Debnath (iD and Prasun Mukherjee (DD *
This work reports the photophysical properties of 1-thioglycerol capped hydrophilic terbium cation incorporated (doped) zinc sulfide [Zn(Tb)S] nanoparticles, which have been post-synthetically modified using $\mathrm{Pb}^{2+}[\mathrm{Zn}(\mathrm{Tb}) \mathrm{S} / \mathrm{Pb}]$ under ambient conditions with $[\mathrm{Zn}(\mathrm{Tb}) \mathrm{S}]:\left[\mathrm{Pb}^{2+}\right]=1: 10^{-5}-1: 10$, essentially providing a scenario with low to heavy co-doping and ultimately the possibility of forming a material of different chemical identity. The effects of selected concentrations of $[\mathrm{Zn}(\mathrm{Tb}) \mathrm{S}]:\left[\mathrm{M}^{n+}\right]=1: 1$ and $1: 10^{-2}$ have also been evaluated for the post-synthetic addition of $\mathrm{Hg}^{2+}, \mathrm{Cd}^{2+}, \mathrm{Ca}^{2+}, \mathrm{Mg}^{2+}, \mathrm{Na}^{+}$and $\mathrm{K}^{+}$. The broad zinc sulfide nanoparticle and sharp $\mathrm{Tb}^{3+}$ emission have different dependence on the relative reactant concentration, with cation identity playing a significant role. The underlying photophysical processes have been rationalized based on the interplay among the (i) cation exchange, (ii) modification of the structural properties of the nanoparticles without necessarily exchanging the cations and (iii) emission enhancement of terbium dopants. In cases where $\mathrm{Tb}^{3+}$ emission is apparent, all the nanoparticles studied demonstrate an optical antenna effect, thus accessing a lower $\mathrm{Tb}^{3+}$ concentration regime compared to in bulk environments. The results presented provide an avenue for the detection of heavy metal ions in general and $\mathrm{Pb}^{2+}$ in particular, with a limit of detection that is at least in the range of sub-ppm, using either the broad ZnS or sharp $\mathrm{Tb}^{3+}$ emission, respectively. This strategy provides an avenue to combine (i) the extremely sensitive and easily accessible analytical technique of photoluminescence spectroscopy, (ii) post-synthetic modification reactions in semiconductor nanoparticles that can be performed with less experimental demand, (iii) time-gated measurement related to the longer luminescence lifetime of terbium cations and (iv) the simultaneous use of broad ZnS nanoparticle and sharp $\mathrm{Tb}^{3+}$ emission from the same assembly, helping eliminate false positive results.
\end{abstract}

Received 19th March 2018 Accepted 28th April 2018

DOI: $10.1039 / \mathrm{c} 8 \mathrm{ra02403k}$

rsc.li/rsc-advances of CdSe nanoparticles under ambient conditions. Moreover, the authors also demonstrated the reversibility of the exchange reaction through the reformation of CdSe nanoparticles by treating the $\mathrm{Ag}_{2} \mathrm{Se}$ nanoparticles with a large excess of $\mathrm{Cd}^{2+}$. This study follows an increasing number of contributions in this field from various research groups, including those from Alivisatos and co-workers. For example, the usefulness of cation exchange reactions in nanomaterials has been demonstrated in the formation of $\mathrm{CdS}-\mathrm{Ag}_{2} \mathrm{~S}$ nanorods via partial exchange, ${ }^{5}$ creation of $\mathrm{CdS}-\mathrm{Cu}_{2} \mathrm{~S}$ nanorods via a formation process that is different compared to that for CdS- $\mathrm{Ag}_{2} \mathrm{~S}$ nanorods, ${ }^{6}$ synthesis of $\mathrm{CdSe} / \mathrm{CdS}$ nanorods to $\mathrm{PbSe} / \mathrm{PbS}$ nanorods through $\mathrm{Cu}_{2} \mathrm{Se} / \mathrm{Cu}_{2} \mathrm{~S}$ assembly, ${ }^{7}$ synthesis of group III-V (InP, InAs, GaP, and GaAs) nanocrystals from cadmium pnictide nanocrystals, ${ }^{8}$ transformation of CdSe (core)-CdS (pod) to $\mathrm{Cu}_{2-x} \mathrm{Se}$ (core) $-\mathrm{Cu}_{2} \mathrm{~S}$ (pod), ${ }^{9}$ sequential formation from CdSe to $\mathrm{Cu}_{2} \mathrm{Se}$ to $\mathrm{ZnSe},{ }^{10}$ transformation of $\mathrm{Cu}_{2} \mathrm{Te}$ to $\mathrm{CdTe},{ }^{11}$ accessing $\mathrm{Cu}_{2} \mathrm{SnSe}_{3}$ and SnSe through treating $\mathrm{Cu}_{2-x} \mathrm{Se}$ with $\mathrm{Sn}^{4+}$ and $\mathrm{Sn}^{2+}$, 
respectively, ${ }^{12}$ doping $\mathrm{Cu}^{2+}$ or $\mathrm{Ag}^{+}$or $\mathrm{Au}^{3+}$ with InAs nanoparticles ${ }^{13}$ and exchange of $\mathrm{Ln}^{3+}$ for $\mathrm{Ln}^{\prime 3+}$, which appears earlier in the periodic table, in $\mathrm{LnF}_{3}$ nanoparticles. ${ }^{14}$ These studies collectively indicate the wide diversity of exchanging the cationic component in semiconductor nanoparticles with another cation that often differs in size and/or charge. Additionally, the cation exchange reaction in semiconductor nanoparticles is faster compared to the corresponding bulk phase reactions, enabling the easy accessibility of these reactions in routine chemical laboratories.

Besides the occurrence of cation exchange reactions in the post-synthetic modification of appropriate semiconductor nanoparticles, other processes may also accompany this sort of chemical manipulation. For example, Murphy and co-workers have shown different photophysical properties in synthetically Mn doped $\mathrm{Zn}(\mathrm{Mn}) \mathrm{S}$ nanoparticles and the corresponding postsynthetically modified undoped $\mathrm{ZnS}$ nanoparticles. ${ }^{15}$ Chrysochoos and co-workers demonstrated modification of the surface properties of $\mathrm{CdS}$ nanoparticles when $\mathrm{Cu}^{2+}$ was added post-synthetically. ${ }^{16}$ Norris and co-workers studied CdSe nanoparticles with post-synthetic modification using $\mathrm{Al}^{3+}, \mathrm{In}^{3+}$ and $\mathrm{Ag}^{+}$and discussed that the outcome of this chemical tuning depends on the dopant identity. ${ }^{17-19}$ Moreover, these authors demonstrated a change in n- to p-type doping with low and high $\mathrm{Ag}^{+}$dopant amounts, and this was correlated to the dopant site being interstitial and substitutional, respectively. Towards a similar end, with regard to the post-synthetic modification of semiconductor nanoparticles, we previously demonstrated the operation of an optical antenna effect in sensitizing $\mathrm{Tb}^{3+}$ and $\mathrm{Eu}^{3+}$ photoluminescence when corresponding nitrate salts were added to a dispersion of $\mathrm{ZnS}$ nanoparticles in chloroform. ${ }^{20}$ Based on the hypothesis of surface sites being less symmetric compared to core sites, a comparison of the $\mathrm{Eu}^{3+}$ asymmetry ratio, luminescence lifetime and lifetime distribution indicates an enhanced surface related contribution in the postsynthetically treated nanoparticles compared to the corresponding synthetically incorporated counterparts. In summary, the post-synthetic modification of semiconductor nanoparticles opens up the possibility of cation exchange, or in cases where such exchange of cations is not feasible, the process may simply tune the surface properties of the nanoparticles, or the externally added cation may reside in the interstitial position of the nanoparticles, thereby tuning the properties of the nanoparticles. However, a systematic investigation of the photophysical properties of post-synthetically modified semiconductor nanoparticles as a function of the relative concentration of reactants is not evident in the literature. Investigating such reactant concentration dependent emission properties in semiconductor nanoparticles is the primary objective of the present study, with the cation identity playing a role in the underlying processes.

This study is organized as follows. Initially, $\mathrm{Zn}(\mathrm{Tb}) \mathrm{S}$ nanoparticles of a fixed concentration were treated post-synthetically with various concentrations of $\mathrm{Pb}^{2+}$ to assess the feasibility of a cation exchange reaction of $\mathrm{Zn}^{2+}: \mathrm{Pb}^{2+}$ and $\mathrm{Tb}^{3+}: \mathrm{Pb}^{2+}$ pairs in the investigated nanoparticles. This is followed by similar experiments using selected relative reactant concentrations of various other cations $\left(\mathrm{Hg}^{2+}, \mathrm{Cd}^{2+}, \mathrm{Ca}^{2+}, \mathrm{Mg}^{2+}, \mathrm{Na}^{+}\right.$, and $\left.\mathrm{K}^{+}\right)$.
Finally, the usefulness of combining post-synthetic modification of semiconductor nanoparticles and photoluminescence spectroscopy has been evaluated for the detection of heavy metal ions in general and $\mathrm{Pb}^{2+}$ in particular.

\section{Materials and methods}

\section{Chemicals}

1-Thioglycerol(3-mercapto-1,2-propanediol) (90+\%), thiourea (99\%), lead nitrate (99\%), mercuric nitrate (99\%), cadmium nitrate $(99 \%)$, calcium nitrate (99\%), magnesium nitrate $(99 \%)$, sodium nitrate $(99 \%)$, potassium nitrate (99\%) and terbium acetate hydrate $(99.9 \%)$ were purchased from Alfa Aesar. Zinc acetate dihydrate (98\%), acetone, methanol and DMF $(N, N$ dimethyl formamide) were purchased from Merck. Coumarin 153 (C153) was purchased from Sigma Aldrich. Argon gas was purchased from Hindustan Gases and Welding. All chemicals were used as purchased without additional purification. The water used in all experiments was obtained from a Millipore system with a resistivity of $18.2 \mathrm{M} \Omega \mathrm{cm}$ at $25{ }^{\circ} \mathrm{C}$.

\section{Nanoparticle synthesis}

The synthesis of hydrophilic ZnS nanoparticles was based on a report by Sarma and co-workers ${ }^{21}$ for undoped $\mathrm{ZnS}$ nanoparticles with additional modifications for terbium incorporated $\mathrm{ZnS}[\mathrm{Zn}(\mathrm{Tb}) \mathrm{S}]$ nanoparticles. ${ }^{22}$ Briefly, $1.98 \mathrm{mmol}$ of zinc acetate hydrate, $1.56 \mathrm{mmol}$ of thiourea, $0.22 \mathrm{mmol}$ of terbium acetate hydrate and $50 \mathrm{ml}$ DMF were loaded into a $100 \mathrm{ml}$ three neck round bottom flask. The solution was degassed under vacuum at room temperature for a period of 30-45 minutes. The reaction was performed under an argon flow and $2.72 \mathrm{mmol}$ of 1-thioglycerol was injected into the solution with the reaction temperature slightly elevated from room temperature. The reaction temperature was then increased to $140{ }^{\circ} \mathrm{C}$ and the solution was refluxed for eight hours. The reaction was stopped by removing the heat source. The nanoparticles were purified through the addition of acetone to the as-synthesized material followed by centrifugation at $4000 \mathrm{rpm}$ for 20 minutes to collect the precipitate. The purification procedure was repeated two times and then the precipitate was dried. The purified nanoparticles were dispersed in water for the electronic spectroscopy measurements.

\section{Post-synthetic modification}

For the post-synthetic modification of the nanoparticles, lead nitrate $\left[\mathrm{Pb}\left(\mathrm{NO}_{3}\right)_{2}\right]$ solutions of varying concentrations were added to a known concentration ${ }^{23}$ (as judged by the molar extinction co-efficient of the nanoparticles) of $\mathrm{Zn}(\mathrm{Tb}) \mathrm{S}$ nanoparticles in a volume/volume manner and this was kept overnight at room temperature to generate the $\mathrm{Zn}(\mathrm{Tb}) \mathrm{S} / \mathrm{Pb}$ nanoparticles. The ratio of $[\mathrm{Zn}(\mathrm{Tb}) \mathrm{S}]:\left[\mathrm{Pb}^{2+}\right]$ was varied from $1: 10^{-5}$ to $1: 10$. For the precipitation of the post-synthetically modified nanoparticles, acetone was added to the dispersion and this was centrifuged for 15 minutes at $3000 \mathrm{rpm}$. A similar procedure was adopted for the corresponding reactions with $\mathrm{M}^{n+}\left(\mathrm{Hg}^{2+}, \mathrm{Cd}^{2+}, \mathrm{Ca}^{2+}, \mathrm{Mg}^{2+}, \mathrm{Na}^{+}\right.$and $\left.\mathrm{K}^{+}\right)$, with $1: 1$ and $1: 10^{-2}$ 
nominal concentrations of $\mathrm{Zn}(\mathrm{Tb}) \mathrm{S}$ and $\mathrm{M}^{n+}$, respectively, to generate the $\mathrm{Zn}(\mathrm{Tb}) \mathrm{S} / \mathrm{M}$ nanoparticles. To perform the reverse post-synthetic modification from the sample with $[\mathrm{Zn}(\mathrm{Tb})$ $\mathrm{S}]:\left[\mathrm{Pb}^{2+}\right]=1: 1,10$ times the amount of $\mathrm{Zn}^{2+}$ precursor that was initially used to make the $\mathrm{Zn}(\mathrm{Tb}) \mathrm{S}$ nanoparticles was added and the $\mathrm{Tb}^{3+}$ content was maintained at a $10 \%$ doping content.

\section{X-ray diffraction}

X-ray powder diffraction was performed using a PANalytical $X$ 'pert PRO diffractometer, operated at a generator voltage of $45 \mathrm{kV}$ and current of $40 \mathrm{~mA}$ with $\mathrm{Cu} \mathrm{K} \alpha$ radiation $(\lambda=0.154 \mathrm{~nm})$ within a $2 \theta$ scan range of $10^{\circ}$ to $80^{\circ}$.

\section{Electron microscopy measurement}

Transmission electron microscopy (TEM) was performed using a JEOL, JEM-2100 model operated with an acceleration potential of $200 \mathrm{kV}$. The TEM samples were prepared by placing a small amount of the nanoparticle dispersion on a carbon coated copper grid followed by drying to remove the excess dispersion. Energy dispersive X-ray spectra (EDS) were collected using a Zeiss model EVO 18 scanning electron microscopy (SEM) instrument.

\section{Photoluminescence spectroscopy}

The photoluminescence spectra were collected using a Horiba Fluorolog 3-22 luminescence spectrometer. The emission spectra were collected through exciting the samples at $280 \mathrm{~nm}$ and the excitation spectra were collected through monitoring the nanoparticle or $\mathrm{Ln}^{3+}$ emission at the appropriate wavelengths. The spectra were collected with an excitation and emission spectral resolution of $4 \mathrm{~nm}$ each. A long pass filter was used to remove the harmonic peak of the excitation source. The solutions used for acquiring the luminescence spectra were prepared so that the absorbance at $280 \mathrm{~nm}$ was $\sim 0.4$. The luminescence spectra were corrected for the absorbance at the excitation wavelength. All measurements were performed at room temperature.

The relative quantum yields $\left(\Phi_{\mathrm{x}}\right)$ of the broad $\mathrm{ZnS}$ nanoparticle emission and sharp $\mathrm{Tb}^{3+}$ emission were calculated separately by comparison to the quantum yield of coumarin 153 (C153) dissolved in methanol ( $\Phi_{\mathrm{r}}=0.42$ (ref. 24)) using eqn (1),

$$
\frac{\Phi_{\mathrm{x}}}{\Phi_{\mathrm{r}}}=\frac{A_{\mathrm{r}}\left(\lambda_{\mathrm{r}}\right) I_{\mathrm{ex}}\left(\lambda_{\mathrm{r}}\right) \eta_{\mathrm{x}}^{2} \int_{0}^{\infty} I_{\mathrm{em}, \mathrm{x}}(\nabla) \mathrm{d} \nabla}{A_{\mathrm{x}}\left(\lambda_{\mathrm{x}}\right) I_{\mathrm{ex}}\left(\lambda_{\mathrm{x}}\right) \eta_{\mathrm{r}}^{2} \int_{0}^{\infty} I_{\mathrm{em}, \mathrm{r}}(\nabla) \mathrm{d} \nabla}
$$

where the subscripts $\mathrm{x}$ and $\mathrm{r}$ refer to the sample and reference, respectively, $A$ is the absorbance at the excitation wavelength $(\lambda)$, $I_{\text {ex }}$ is the intensity of the excitation light at the same wavelength, $\eta$ is the refractive index $(\eta=1.333$ for water and $\eta=1.327$ for methanol) and $I_{\mathrm{em}}(\vec{\nu})$ is the luminescence intensity as a function of wavenumber $\bar{\nu}$. The $\mathrm{Tb}^{3+}$ emission was extracted from the experimentally observed $\mathrm{Zn}(\mathrm{Tb}) \mathrm{S}$ nanoparticles emission spectrum by interpolating a baseline that corroborates with the $\mathrm{ZnS}$ nanoparticles emission only. For example, to obtain the $\mathrm{Tb}^{3+}$ emission band centered around $545 \mathrm{~nm}$, first the experimentally observed emission spectrum of the $\mathrm{Zn}(\mathrm{Tb}) \mathrm{S}$ nanoparticles was interpolated with two data points in the wavelength range $520-570 \mathrm{~nm}$, and this was further interpolated with data points having $1 \mathrm{~nm}$ data intervals, the same as that which was used for the experimental spectrum acquisition. A similar protocol was adopted to extract the other $\mathrm{Tb}^{3+}$ emission bands centered at 490, 585 and $620 \mathrm{~nm}$. This interpolated background contribution was subsequently subtracted from the experimentally observed emission spectrum of the $\mathrm{Zn}(\mathrm{Tb}) \mathrm{S}$ nanoparticles to extract the separate contribution of the broad and sharp $\mathrm{ZnS}$ nanoparticles and $\mathrm{Tb}^{3+}$ emission, respectively.

\section{Results and discussion}

Fig. 1 (panels a-d) shows images of samples where the $\mathrm{Zn}(\mathrm{Tb}) \mathrm{S}$ nanoparticles have been treated with varying concentrations of $\mathrm{Pb}^{2+}$ post-synthetically. While the $\mathrm{Zn}(\mathrm{Tb}) \mathrm{S}$ nanoparticles appear white to naked eye (panel a), gradual addition of $\mathrm{Pb}^{2+}$ transforms the color of the nanoparticles to off-white (panels b and c) and eventually brownish (panel d). This color change clearly indicates that the identity of the $\mathrm{Zn}(\mathrm{Tb}) \mathrm{S}$ nanoparticles changes via the post-synthetic modification with $\mathrm{Pb}^{2+}$ under ambient conditions, further suggesting the formation of a lower band gap material.

The corresponding electronic absorption spectra are shown in panels e-h of Fig. 1. The $\mathrm{Zn}(\mathrm{Tb}) \mathrm{S}$ nanoparticles show characteristic absorption in the ultraviolet spectral range, which is consistent with higher band gap values. On increasing the concentration of $\mathrm{Pb}^{2+}$, the absorption contribution in the visible spectral region increases. In the sample with $[\mathrm{Zn}(\mathrm{Tb})$ $\mathrm{S}]:\left[\mathrm{Pb}^{2+}\right]=1: 10$, the signature in the ultraviolet spectral range changes dramatically and concomitantly the contribution from visible absorption increases. This gradual change in the electronic absorption behavior of the samples is reflected in their color and can be perceived visually.

\section{X-ray diffraction}

XRD patterns of the synthesized $\mathrm{Zn}(\mathrm{Tb}) \mathrm{S}$ nanoparticles show features at $2 \theta=28.5^{\circ}, 47.5^{\circ}$ and $56.2^{\circ}$ corresponding to the (111), (220) and (311) planes of cubic zinc sulfide [The Joint Committee on Powder Diffraction Standards (JCPDS) card number: 05-0566], see Fig. 2. The typical bands of terbium sulfide were not overtly visible in the obtained profile of the $\mathrm{Zn}(\mathrm{Tb}) \mathrm{S}$ nanoparticles. The XRD patterns of the nanoparticles with $[\mathrm{Zn}(\mathrm{Tb}) \mathrm{S}]:\left[\mathrm{Pb}^{2+}\right]=1: 1$ show major bands at $2 \theta=25.3^{\circ}$, $30.3^{\circ}, 43.0^{\circ}, 50.9^{\circ}, 53.4^{\circ}, 62.5^{\circ}, 68.5^{\circ}$ and $70.9^{\circ}$ corresponding to the (111), (200), (220), (311), (222), (400), (331) and (420) planes of cubic lead sulfide [JCPDS card number: 05-0592] strongly indicating that addition of $\mathrm{Pb}^{2+}$ to the $\mathrm{Zn}(\mathrm{Tb}) \mathrm{S}$ nanoparticles leads to cation exchange of $\mathrm{Zn}^{2+}$ with $\mathrm{Pb}^{2+}$. It is worth noting that some bands at $2 \theta=34.1^{\circ}, 56.4^{\circ}$ and $59.1^{\circ}$ were left unassigned by us, and through a process of comparison of all the XRD peaks of terbium sulfide, we concluded that these bands are of non-noticeable contributions.

\section{Electron microscopy}

The transmission electron microscopy (TEM) images of the $\mathrm{Zn}(\mathrm{Tb}) \mathrm{S}$ nanoparticles and the particles which resulted from the 


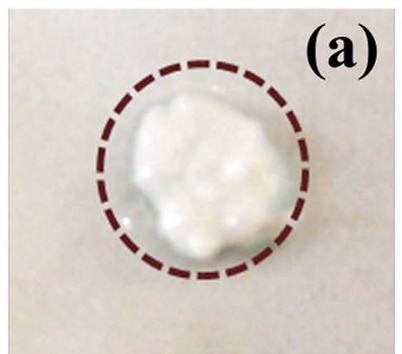

$\operatorname{Zn}(\mathbf{T b}) S$

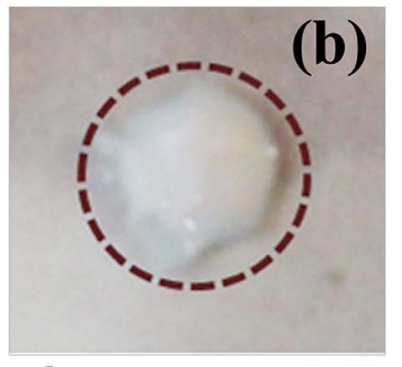

$1: 10^{-5}$

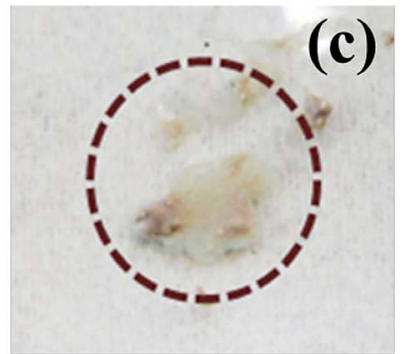

$1: 10^{-2}$

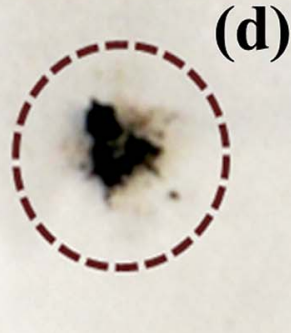

$1: 10$

\section{$[\mathrm{Zn}(\mathrm{Tb}) \mathrm{S}]:\left[\mathrm{Pb}^{2+}\right]$}
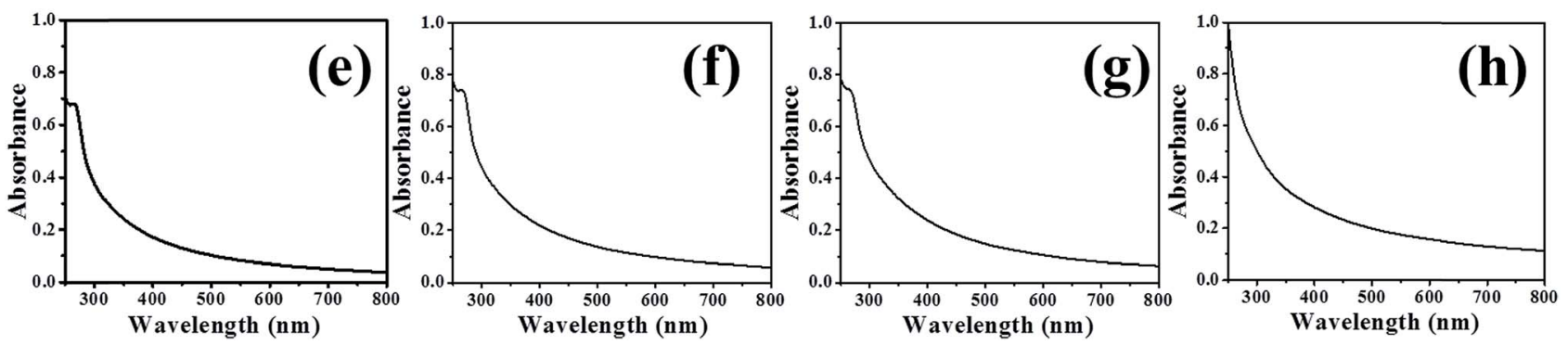

Fig. 1 Images of the nanoparticles with various compositions are presented in panels (a)-(d), clearly showing a change in color due to the postsynthetic modification of the $\mathrm{Zn}(\mathrm{Tb}) \mathrm{S}$ nanoparticles using $\mathrm{Pb}^{2+}$. The photographs were taken with an Olympus digital camera (model: E-PL1). The corresponding electronic absorption spectra are shown in panels (e)-(h).

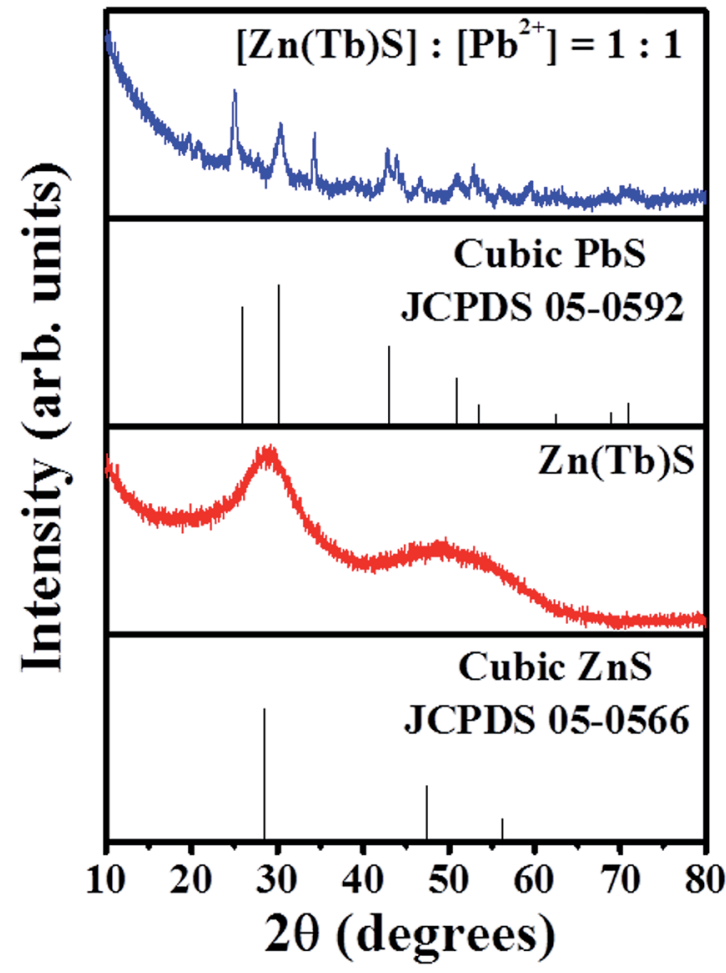

Fig. 2 XRD profiles of the $\mathrm{Zn}(\mathrm{Tb}) \mathrm{S}$ nanoparticles and the sample with $[\mathrm{Zn}(\mathrm{Tb}) \mathrm{S}]:\left[\mathrm{Pb}^{2+}\right]=1: 1$ are shown. post-synthetic treatment of the $\mathrm{Zn}(\mathrm{Tb}) \mathrm{S}$ nanoparticles with a nominal $[\mathrm{Zn}(\mathrm{Tb}) \mathrm{S}]:\left[\mathrm{Pb}^{2+}\right]=1: 1$ are presented in panels a and e of Fig. 3. The corresponding size distributions are shown in panels $b$ and $f$. Collectively, these show the formation of particles that are spherical in shape with average diameters of $3.0 \pm 0.5 \mathrm{~nm}$ and $3.9 \pm 0.6 \mathrm{~nm}$, respectively, before and after $\mathrm{Pb}^{2+}$ treatment. This suggests that the post-synthetic modification of the $\mathrm{Zn}(\mathrm{Tb}) \mathrm{S}$ nanoparticles with the given composition results in particles with a marginally increased size. The high resolution transmission electron microscopy (HRTEM) images shown in panels c and g of Fig. 3 identify different inter-planar distances that are correlated with the (111) and (200) planes of $\mathrm{ZnS}$ and PbS, respectively [JCPDS card numbers: 05-0566 and 05-0592 for ZnS and PbS, respectively]. Further support of this comes from the selected area electron diffraction (SAED) patterns, shown in panels $\mathrm{d}$ and $\mathrm{h}$, identifying the different planes of $\mathrm{ZnS}$ and $\mathrm{PbS}$, respectively. These measurements clearly identify the formation of a material of different chemical identity via the post-synthetic modification of the $\mathrm{Zn}(\mathrm{Tb}) \mathrm{S}$ nanoparticles with $\mathrm{Pb}^{2+}$.

The data presented in Fig. 3, while identifying the particle morphology with crystal information for the two extremes, does not directly shed light on the behaviour of the intermediate samples that have been prepared with various amounts of postsynthetically added $\mathrm{Pb}^{2+}$. To address this, corresponding electron microscopy experiments were undertaken with the samples 

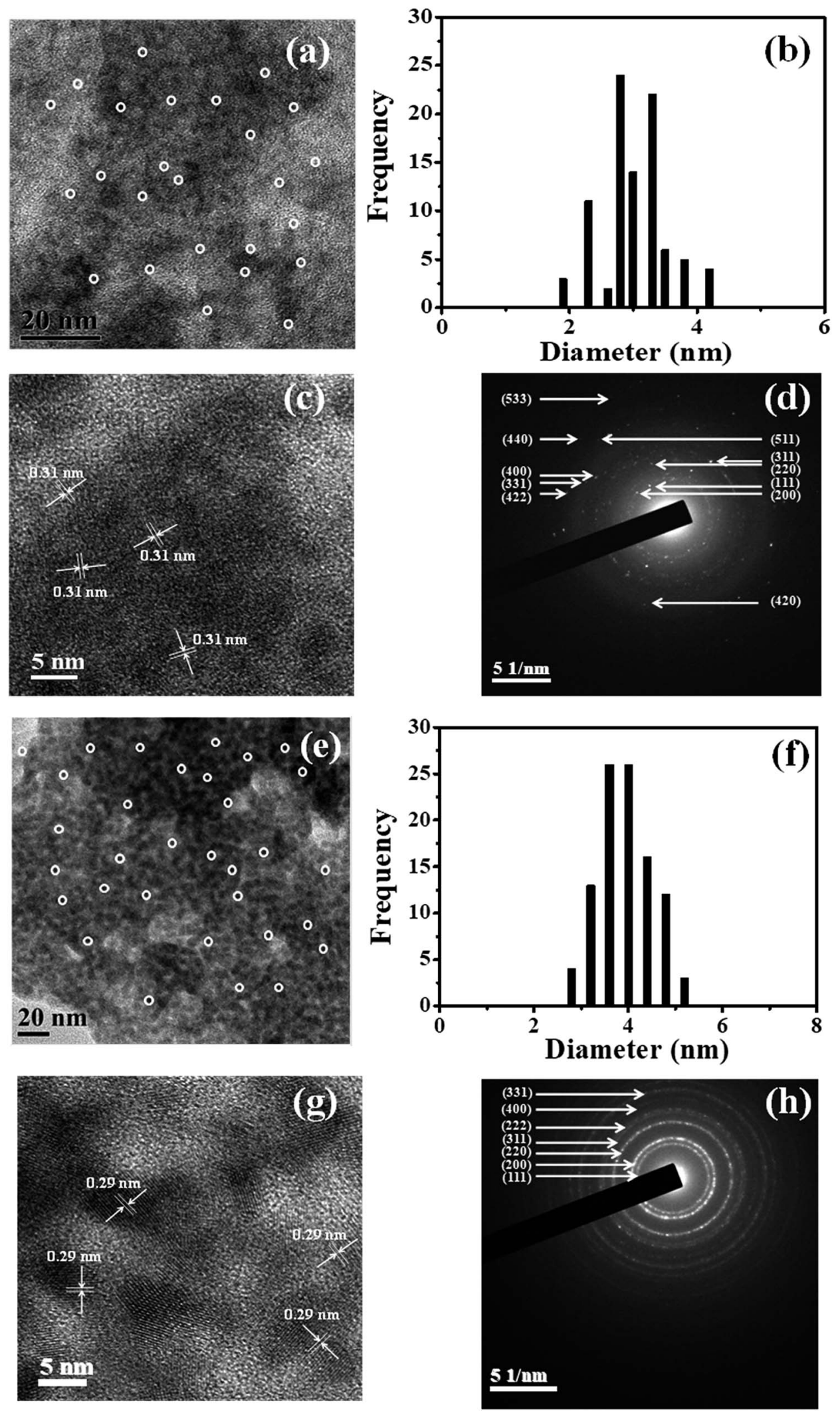

Fig. 3 The TEM images, size distributions, HRTEM images and SAED patterns of the Zn(Tb)S and post-synthetically modified Zn(Tb)S nanoparticles with $[\mathrm{Zn}(\mathrm{Tb}) \mathrm{S}]:\left[\mathrm{Pb}^{2+}\right]=1: 1$ are shown in panels (a) and (e), (b) and (f), (c) and (g), and (d) and (h), respectively. 
having $[\mathrm{Zn}(\mathrm{Tb}) \mathrm{S}]:\left[\mathrm{Pb}^{2+}\right]=1: 10^{-4}$ and $[\mathrm{Zn}(\mathrm{Tb}) \mathrm{S}]:\left[\mathrm{Pb}^{2+}\right]=$ $1: 10^{-2}$, and the data are shown in Fig. 4. For these two samples, particle diameters of $3.0 \pm 0.5$ and $3.2 \pm 0.4$, respectively, were observed. Moreover, the HRTEM and SAED patterns of these samples only reveal characteristic crystal planes that could be correlated with cubic zinc sulfide. This suggests that within the detection capability of the electron microscopy measurements performed in the present work, the formation of lead sulfide is not apparent using these reactant concentration ratios and $\mathrm{Pb}^{2+}$ is present as a dopant entity in the $\mathrm{Zn}(\mathrm{Tb}) \mathrm{S}$ nanoparticles. However, to this end, we note that elemental mapping would better address any specific and minor alterations in the $\mathrm{Zn}(\mathrm{Tb}) \mathrm{S}$ crystal during the post-synthetic modification of the nanoparticles. In general, elemental mapping of lanthanide incorporated semiconductor nanoparticles would reveal more detailed structural information with regard to the dopant spatial location in the semiconductor nanoparticles, however, the smaller dimension of the materials studied $(\sim 3 \mathrm{~nm}$ in diameter) has restricted our efforts so far in obtaining elemental mapping using the available TEM facilities.

To summarize, both the $\mathrm{Zn}(\mathrm{Tb}) \mathrm{S}$ and $\mathrm{PbS}$ nanoparticles that have been prepared using $[\mathrm{Zn}(\mathrm{Tb}) \mathrm{S}]:\left[\mathrm{Pb}^{2+}\right]=1: 1$ form cubic phases. The lattice parameters for the ZnS cubic phase are $a=$ $b=c=5.406 \AA, \alpha=\beta=\gamma=90^{\circ}$ and for the $\mathrm{PbS}$ cubic phase the corresponding values are $a=b=c=5.936 \AA, \alpha=\beta=\gamma=90^{\circ}$. These values indicate an increase in the volume of the nanoparticles upon transformation via cation exchange. As shown in Fig. 3, the diameter of the nanoparticles increases marginally following the post-synthetic modification of the $\mathrm{Zn}(\mathrm{Tb}) \mathrm{S}$ nanoparticles. This observation is in corroboration with the expected trend based on the crystal parameters.

\section{Elemental composition}

Energy dispersive X-ray spectroscopy (EDS) was used to determine the elemental composition of the synthesized nanoparticles. EDS is known to provide quantitative information on the elemental composition in nanomaterials. ${ }^{14}$ While the elemental composition determined from the EDS measurements does not identify the absolute concentrations of the elements, it does provide the relative concentrations of the components. Representative EDS spectra are shown in panels $a$ and $b$ of Fig. 5, with the spectral profiles for the other systems shown in Fig. S1 (ESI $\dagger$ ). The elemental compositions of the nanoparticles as a function of $\left[\mathrm{Pb}^{2+}\right]$ are summarized in panel $\mathrm{c}$ of Fig. 5. The corresponding atomic percentage values and related information are tabulated in Tables S1 and S2. $\dagger$ The EDS of the investigated $\mathrm{Zn}(\mathrm{Tb}) \mathrm{S}$ nanoparticles reveals the characteristic bands of $\mathrm{Zn}, \mathrm{Tb}$ and $\mathrm{S}$ (panel a). With a gradual increase in $\left[\mathrm{Pb}^{2+}\right]$, the post-synthetically modified nanoparticles show a marginal increase in the $\mathrm{Pb}^{2+}$ content. However, the amount of $\mathrm{Zn}, \mathrm{Tb}$ and $\mathrm{S}$ remains appreciable. Post-synthetic modification of the $\mathrm{Zn}(\mathrm{Tb}) \mathrm{S}$ nanoparticles with a nominal [ $\mathrm{Zn}(\mathrm{Tb})$ $\mathrm{S}]:\left[\mathrm{Pb}^{2+}\right]=1: 1$ leads to a disappearance and marginal presence of the $\mathrm{Zn}$ and $\mathrm{Tb}$ bands, respectively, in the EDS, with a concomitant appearance of a $\mathrm{Pb}$ signature (panel b). This suggests that the cation exchange reaction of the $\mathrm{Zn}^{2+}: \mathrm{Pb}^{2+}$ pair is more facile compared to that of the $\mathrm{Tb}^{3+}: \mathrm{Pb}^{2+}$ pair. In the case where $\left[\mathrm{Pb}^{2+}\right]$ has been further increased to $[\mathrm{Zn}(\mathrm{Tb})$ $\mathrm{S}]:\left[\mathrm{Pb}^{2+}\right]=1: 10$, the complete disappearance of the $\mathrm{Tb}$ band occurs as well, with the signature of $\mathrm{Pb}$ being the sole cationic ingredient in the nanoparticles. This, along with the presence of an $\mathrm{S}$ band in the EDS, suggests the cation exchange of both $\mathrm{Zn}^{2+}$ and $\mathrm{Tb}^{3+}$ with the post-synthetically added $\mathrm{Pb}^{2+}$ and the formation of $\mathrm{PbS}$ nanoparticles with this relative concentration ratio. Many previous reports on cation exchange reactions have used a stoichiometric excess of the incoming cation compared to the outgoing cation in order to make the cation exchange reaction in semiconductor nanoparticles reach completion., ${ }^{4,25,26}$ This can be visualized with the concept of a limiting reagent. The relative concentrations of $[\mathrm{Zn}(\mathrm{Tb}) \mathrm{S}]:\left[\mathrm{Pb}^{2+}\right]=1: 10^{-5}-1: 10$ cover scenarios ranging from a low to heavy amount co-doping and ultimately the formation of a material of different chemical identity. In this kind of reaction, any change in charge mismatch in the cationic components could be observed through the formation of appropriate defects and role of the surface capping ligands of the nanoparticles. On the other hand, any deviation in the size of the cations might be associated with a lattice distortion, as has been discussed by Banin and co-workers ${ }^{13}$ for doping $\mathrm{Cu}^{2+}, \mathrm{Ag}^{+}$and $\mathrm{Au}^{3+}$ in InAs nanoparticles and by Chen and coworkers ${ }^{27}$ for doping $\mathrm{Eu}^{3+}$ in $\mathrm{TiO}_{2}$ nanoparticles. In the following section, the impact of post-synthetic modification of $\mathrm{Zn}(\mathrm{Tb}) \mathrm{S}$ nanoparticles as a function of $\left[\mathrm{Pb}^{2+}\right]$ has been studied using photoluminescence spectroscopy (vide infra).

\section{Photoluminescence spectra of the $\mathrm{Zn}(\mathrm{Tb}) \mathrm{S} / \mathrm{Pb}$ nanoparticles}

Based on the trend observed in the EDS measurements, it could be expected that the photoluminescence properties of the $\mathrm{Zn}(\mathrm{Tb}) \mathrm{S}$ nanoparticles as a function of $\left[\mathrm{Pb}^{2+}\right]$ would be nearly independent up to $[\mathrm{Zn}(\mathrm{Tb}) \mathrm{S}]:\left[\mathrm{Pb}^{2+}\right]=1: 1$, following which a change in the spectral properties would be visible due to the formation of PbS nanoparticles via cation exchange. However, the experimentally observed trend has been found to have additional contributions that deviate from the spectral outcome predicted with this simplistic expectation. The following text first presents the data from photoluminescence spectroscopy measurements, and the roles of various processes in determining the spectral outcome are discussed.

The photoluminescence excitation and emission spectra of the $\mathrm{Zn}(\mathrm{Tb}) \mathrm{S}$ nanoparticles with post-synthetic modifications, through adding $\mathrm{Pb}^{2+}$ solutions with various $\left[\mathrm{Pb}^{2+}\right]$, are presented in Fig. 6. Exciting the nanoparticles at $280 \mathrm{~nm}$, the $\mathrm{Zn}(\mathrm{Tb}) \mathrm{S}$ nanoparticles reveal a characteristic broad emission band at $400 \mathrm{~nm}$ that is intrinsic to $\mathrm{ZnS}$ based materials and has been correlated to sulfur related vacancies..$^{15,28-30}$ Additionally, the $\mathrm{Zn}(\mathrm{Tb}) \mathrm{S}$ nanoparticles show characteristic sharp emissions of $\mathrm{Tb}^{3+}$ at 490, 545, 585 and $620 \mathrm{~nm}$ that arise from the ${ }^{5} \mathrm{D}_{4} \rightarrow$ ${ }^{7} \mathrm{~F}_{n}[n=6-3]$ transitions, respectively. These observations are consistent with our previous studies. ${ }^{20,22,30-32}$ The broad and sharp emissions of $\mathrm{ZnS}$ and $\mathrm{Tb}^{3+}$, respectively, in the $\mathrm{Zn}(\mathrm{Tb}) \mathrm{S}$ nanoparticles behave almost independently. It is worth noting that there exists million-fold differences between the radiative rates of the nanoparticles and $\mathrm{Tb}^{3+}$ intrinsic population decay 

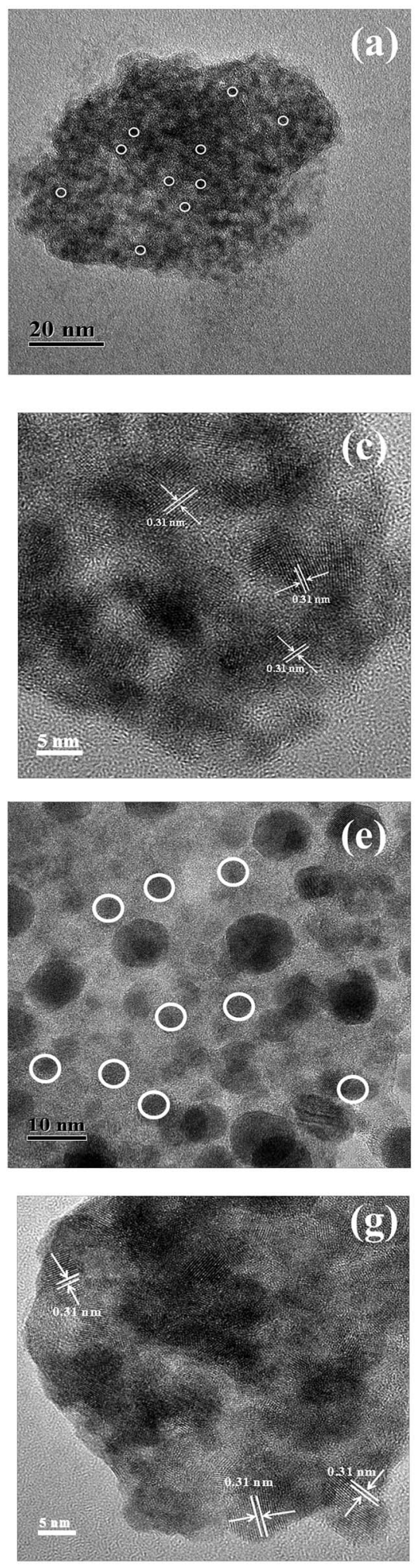
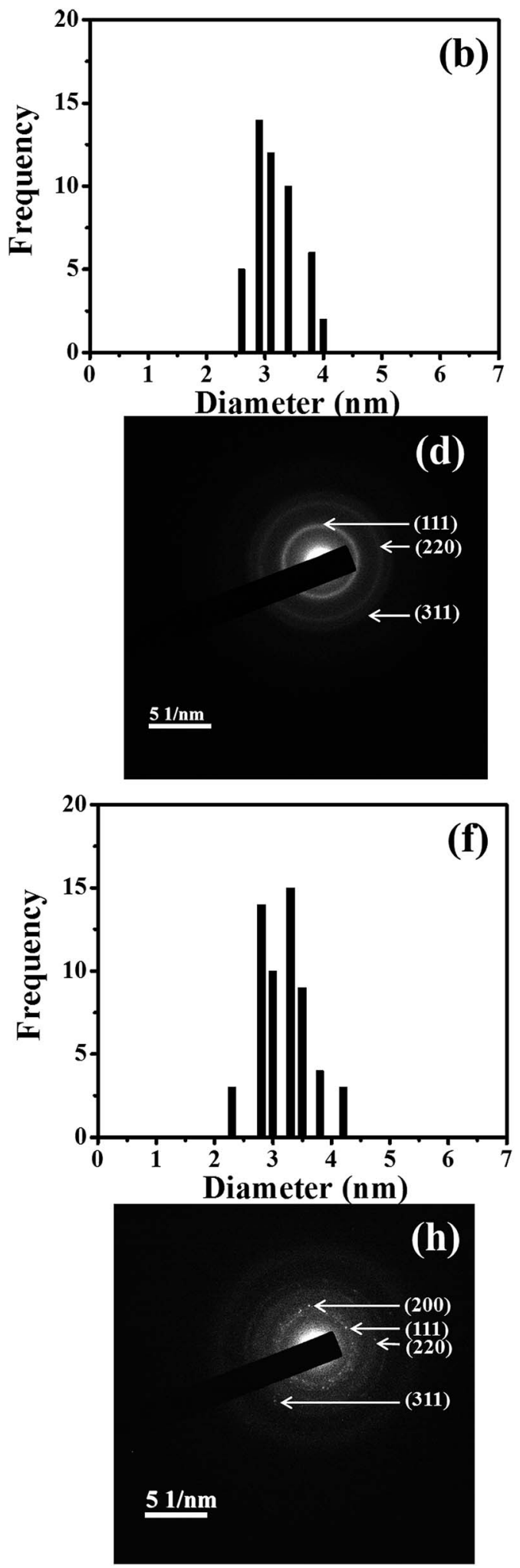

Fig. 4 The TEM images, size distributions, HRTEM images and SAED patterns of the post-synthetically modified Zn(Tb)S nanoparticles with $[\mathrm{Zn}(\mathrm{Tb}) \mathrm{S}]:\left[\mathrm{Pb}^{2+}\right]=1: 10^{-4}$ and $1: 10^{-2}$ are shown in panels (a) and (e), (b) and (f), (c) and (g), and (d) and (h), respectively. To calculate the size distribution only non-agglomerated particles were considered.

kinetics. While the photoluminescence lifetimes of the $\mathrm{ZnS}$ nanoparticles are in the range of nanoseconds, these are in the order of milliseconds for the $\mathrm{Tb}^{3+}$ emission.
In the case where the $\mathrm{Zn}(\mathrm{Tb}) \mathrm{S}$ nanoparticles have been treated post-synthetically with $\mathrm{Pb}^{2+}$ of various concentrations, a non-monotonous trend has been observed in the emission 

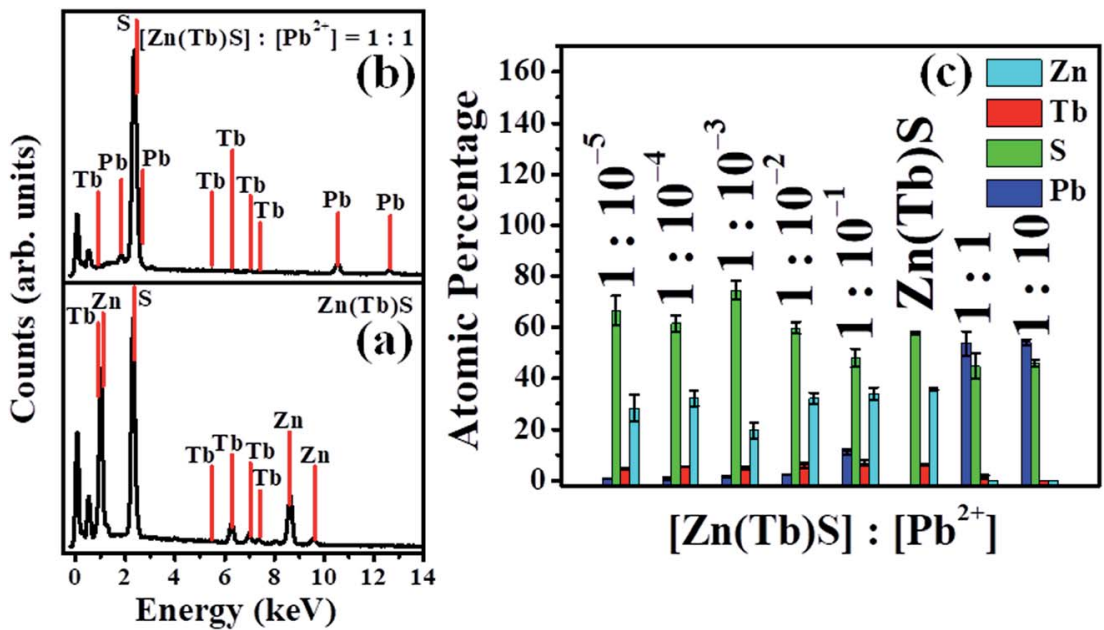

Fig. 5 Panels (a) and (b) show the EDS spectra of the $\mathrm{Zn}(\mathrm{Tb}) \mathrm{S}$ and post-synthetically modified $\mathrm{Zn}(\mathrm{Tb}) \mathrm{S}$ nanoparticles with [Zn(Tb)S] : [Pb $\left.{ }^{2+}\right]=1: 1$, respectively. Panel (c) shows the elemental composition of the $\mathrm{Zn}(\mathrm{Tb}) \mathrm{S}$ nanoparticles with various $\mathrm{Pb}^{2+}$ concentrations that have been added post-synthetically.

behavior. A comparative summary of the relative intensities of the broad $\mathrm{ZnS}$ based nanoparticles emission centered at $400 \mathrm{~nm}$ and sharp $\mathrm{Tb}^{3+}$ emission as a function of $\left[\mathrm{Pb}^{2+}\right]$ is presented in Fig. 7. The broad ZnS nanoparticles based emission decreases dramatically in the post-synthetically modified nanoparticles with $[\mathrm{Zn}(\mathrm{Tb}) \mathrm{S}]:\left[\mathrm{Pb}^{2+}\right]=1: 1$ and $1: 10$, with respect to the corresponding intensity in the $\mathrm{Zn}(\mathrm{Tb}) \mathrm{S}$ nanoparticles. The $[\mathrm{Zn}(\mathrm{Tb}) \mathrm{S}]:\left[\mathrm{Pb}^{2+}\right]<1: 1$ could be categorized differently. In the cases with $[\mathrm{Zn}(\mathrm{Tb}) \mathrm{S}]:\left[\mathrm{Pb}^{2+}\right]=1: 10^{-1}-1: 10^{-3}$ the broad emission is significantly lowered. It is noticeable that even when this ratio is $1: 10^{-4}$, the emission decreases by a distinguishable extent. On the other hand, with this ratio being $1: 10^{-5}$ this emission is comparable in magnitude to that observed in the $\mathrm{Zn}(\mathrm{Tb}) \mathrm{S}$ nanoparticles. Similar analysis for the sharp $\mathrm{Tb}^{3+}$ emission reveals a decreased emission in the $1: 1$ and $1: 10$ cases with respect to that observed in the $\mathrm{Zn}(\mathrm{Tb}) \mathrm{S}$
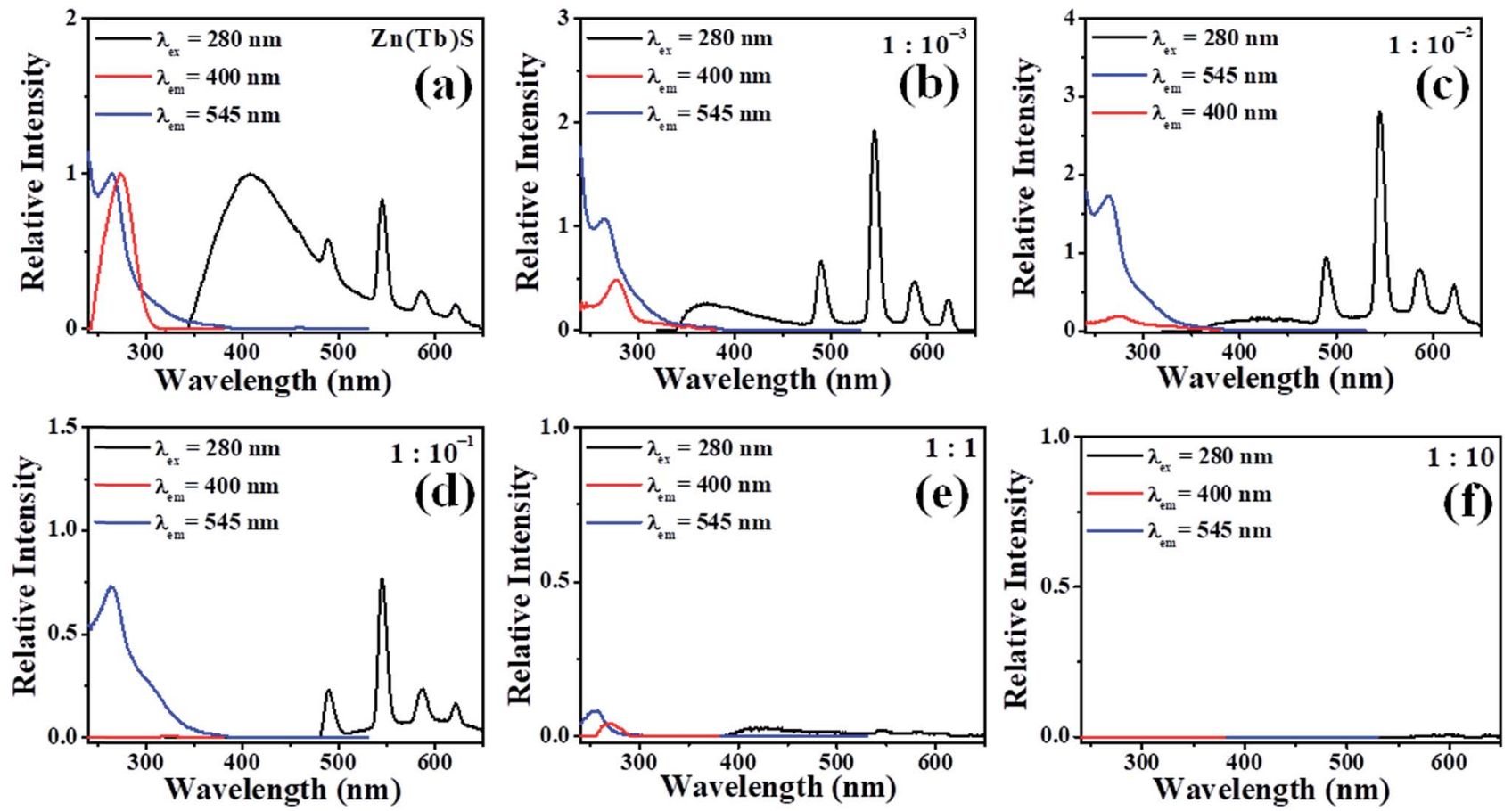

Fig. 6 Photoluminescence excitation $\left(\lambda_{\mathrm{em}}=400 \mathrm{~nm}\right.$ and $\left.545 \mathrm{~nm}\right)$ and emission $\left(\lambda_{\mathrm{ex}}=280 \mathrm{~nm}\right) \mathrm{spectra}$ of $[\mathrm{Zn}(\mathrm{Tb}) \mathrm{S}]:\left[\mathrm{Pb}{ }^{2+}\right]$ with various concentrations of $\mathrm{Pb}^{2+}$ are shown, with the numbers in each panel indicating the nominal $[\mathrm{Zn}(\mathrm{Tb}) \mathrm{S}]:\left[\mathrm{Pb}^{2+}\right]$. The concentration of the $\mathrm{Zn}(\mathrm{Tb}) \mathrm{S}$ nanoparticles was $0.3 \mathrm{mM}$. The intensity at the peak position of the $\mathrm{Zn}(\mathrm{Tb}) \mathrm{S}$ nanoparticles has been normalized to unity and all other spectra have been presented with respect to this band. 

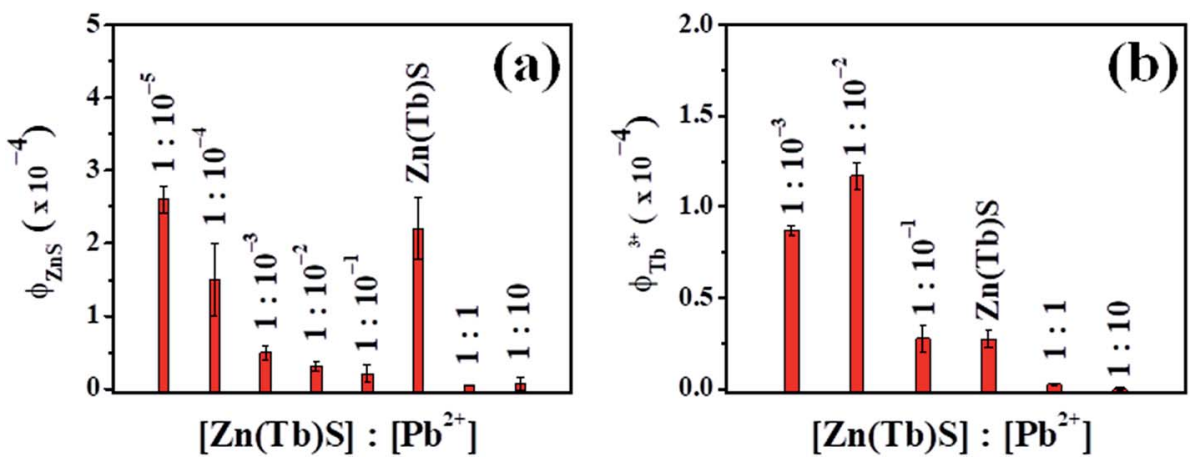

Fig. 7 Plots of the relative intensities of the broad and sharp emission of the ZnS nanoparticles (panel a) and Tb ${ }^{3+}$ (panel b), respectively, are shown, where the $\mathrm{Zn}(\mathrm{Tb}) \mathrm{S}$ nanoparticles were modified post-synthetically using $\mathrm{Pb}^{2+}$ with various concentrations. For the quantum yield calculations, the broad emission band of ZnS centered around $400 \mathrm{~nm}$ was used and for $\mathrm{Tb}^{3+}$ emission all four experimentally observed emission bands centered around 490,545, 585 and $620 \mathrm{~nm}$, respectively, originating from ${ }^{5} \mathrm{D}_{4} \rightarrow{ }^{7} \mathrm{~F}_{n}[n=6-3]$ were used. The values reported are generally the average and standard deviation from three independent measurements.

nanoparticles, whereas in the $1: 10^{-2}-1: 10^{-3}$ cases the $\mathrm{Tb}^{3+}$ emission gets enhanced. In the $1: 10^{-1}$ case, any change in the $\mathrm{Tb}^{3+}$ emission compared to that observed in the $\mathrm{Zn}(\mathrm{Tb}) \mathrm{S}$ nanoparticles is not evident. Clearly, competitive factors play a role and these factors are discussed in the following text. The data presented in Fig. 7 as average and standard deviation include variation from the independent synthesis of the $\mathrm{Zn}(\mathrm{Tb})$ $\mathrm{S}$ nanoparticles and subsequent post-synthetic modification. For $[\mathrm{Zn}(\mathrm{Tb}) \mathrm{S}]:\left[\mathrm{Pb}^{2+}\right]=1: 10^{-4}-1: 10^{-5}$, the trend in $\mathrm{Tb}^{3+}$ emission did not result in a trend with quantitative agreement and hence these data are not included. In these two samples, unfortunately we could not generate reproducible data. The non-reproducibility of the $\mathrm{Tb}^{3+}$ emission quantum yield might be associated with the difficulty in controlling the subtle electronic interactions between $\mathrm{Tb}^{3+}$ and the small amount of postsynthetically added $\mathrm{Pb}^{2+}$ from the post-synthetic treatment with an aqueous dispersion of the $\mathrm{Zn}(\mathrm{Tb}) \mathrm{S}$ nanoparticles prepared independently.

The photoluminescence excitation spectra (Fig. 6) of the different studied nanoparticles monitoring the broad emission band centered at $400 \mathrm{~nm}$, in the cases where emission is prominent, reveal a broad band centered around $280 \mathrm{~nm}$, which has been assigned to the band gap transition of the $\mathrm{Zn}(\mathrm{Tb}) \mathrm{S}$ nanoparticles. Excitation spectra were also acquired, monitoring the $\mathrm{Tb}^{3+}$ emission at $545 \mathrm{~nm}$. These spectra provide information about the electronic structures that are responsible for generating the $\mathrm{Tb}^{3+}$ emission. The relevant spectral profile for the $\mathrm{Zn}(\mathrm{Tb}) \mathrm{S}$ nanoparticles reveals a broad band centered around $280 \mathrm{~nm}$ and most remarkably this profile is devoid of significant contributions from direct $4 \mathrm{f}-4 \mathrm{f}$ sharp excitation bands, suggesting the operation of an optical antenna effect. Moreover, in the post-synthetically modified nanoparticles (wherever $\mathrm{Tb}^{3+}$ emission is evident), the corresponding spectral profile conserves the general feature of broadness, suggesting the operation of an optical antenna effect to sensitize the $\mathrm{Tb}^{3+}$ luminescence in the nanoparticles studied.

It has been argued that with the variation of reactant concentration from $[\mathrm{Zn}(\mathrm{Tb}) \mathrm{S}]:\left[\mathrm{Pb}^{2+}\right]=1: 10^{-5}-1: 10$, it is possible to access scenarios that involve low to heavily co-doped nanoparticles without significant contributions from ternary mixtures. Given the formation of a ternary mixture, (i) distinct terbium sulfide and lead sulfide phases should have been observed in the HRTEM and SAED patterns and (ii) the photoluminescence excitation spectrum, upon monitoring the $\mathrm{Tb}^{3+}$ emission at $545 \mathrm{~nm}$, would have more contribution from the direct sharp intra-configurational $4 \mathrm{f}-4 \mathrm{f}$ bands due to the contribution from more surface related terbium atoms in the nanoparticles. As none of these effects have been clearly observed we exclude the possibility of formation of a ternary mixture at least in the relative reactant concentrations studied and emphasise the importance of the formation of co-doped nanoparticles.

The trend in the photoluminescence spectra combined with the elemental composition as determined from the EDS has been rationalized by the following processes.

(a) Cation exchange. Determining the emission of the $\mathrm{Zn}(\mathrm{Tb}) \mathrm{S}$ nanoparticles as a function of $\left[\mathrm{Pb}^{2+}\right]$ provides an opportunity to assess the cation exchange of $\mathrm{Zn}^{2+}: \mathrm{Pb}^{2+}$ and $\mathrm{Tb}^{3+}: \mathrm{Pb}^{2+}$ pairs. For the nanoparticles with higher $[\mathrm{Zn}(\mathrm{Tb})$ $\mathrm{S}]:\left[\mathrm{Pb}^{2+}\right]$, the characteristic broad $\mathrm{ZnS}$ based nanoparticles and sharp $\mathrm{Tb}^{3+}$ emission were both found to be present, suggesting that a lower relative $\left[\mathrm{Pb}^{2+}\right]$ with $[\mathrm{Zn}(\mathrm{Tb}) \mathrm{S}]:\left[\mathrm{Pb}^{2+}\right]=1: 10^{-5}$ is unable to alter the composition of the $\mathrm{Zn}(\mathrm{Tb}) \mathrm{S}$ nanoparticles to a significant extent. With this reactant ratio being $1: 10^{-4}$, the broad emission decreases by $\sim 30 \%$ in intensity, compared to that observed in the $\mathrm{Zn}(\mathrm{Tb}) \mathrm{S}$ nanoparticles. With a gradual increase in the relative amount of $\mathrm{Pb}^{2+}$, the broad emission characteristic of the ZnS based nanoparticles centered around $400 \mathrm{~nm}$ disappears significantly at around a nominal [ $\mathrm{Zn}(\mathrm{Tb})$ $\mathrm{S}]:\left[\mathrm{Pb}^{2+}\right]=1: 10^{-3}-1: 10^{-1}$ and eventually with further increase in $\left[\mathrm{Pb}^{2+}\right]$ to around a nominal $[\mathrm{Zn}(\mathrm{Tb}) \mathrm{S}]:\left[\mathrm{Pb}^{2+}\right]=1: 1$ the characteristic sharp $\mathrm{Tb}^{3+}$ emission bands almost disappear, as evident from Fig. 6 and 7. The $\mathrm{Tb}^{3+}$ emission disappears completely with a nominal $[\mathrm{Zn}(\mathrm{Tb}) \mathrm{S}]:\left[\mathrm{Pb}^{2+}\right]=1: 10$. It is remarkable to note that both the $\mathrm{ZnS}$ nanoparticle centered broad emission around $400 \mathrm{~nm}$ and the characteristic sharp $\mathrm{Tb}^{3+}$ emission bands at 490, 545, 585 and $620 \mathrm{~nm}$ were found to be absent in the emission spectrum in cases with a nominal 
$[\mathrm{Zn}(\mathrm{Tb}) \mathrm{S}]:\left[\mathrm{Pb}^{2+}\right]=1: 10$. This suggests that the post-synthetic modification of the $\mathrm{Zn}(\mathrm{Tb}) \mathrm{S}$ nanoparticles with $\mathrm{Pb}^{2+}$ results in a complete displacement of the $\mathrm{Zn}^{2+}$ and $\mathrm{Tb}^{3+}$ from the nanoparticles, albeit with a greater ease for the $\mathrm{Zn}^{2+}: \mathrm{Pb}^{2+}$ pair compared to the $\mathrm{Tb}^{3+}: \mathrm{Pb}^{2+}$ pair. These findings are qualitatively consistent with the EDS measurements (vide supra). To summarize, the post-synthetic treatment of the $\mathrm{Zn}(\mathrm{Tb}) \mathrm{S}$ nanoparticles with $\mathrm{Pb}^{2+}$ having a nominal $[\mathrm{Zn}(\mathrm{Tb}) \mathrm{S}]:\left[\mathrm{Pb}^{2+}\right]=1: 10$ or even $1: 1$ results in a complete or near complete (see Table $\mathrm{S} 1 \dagger$ ) displacement of $\mathrm{Zn}^{2+}$ and $\mathrm{Tb}^{3+}$, with the formation of $\mathrm{PbS}$ nanoparticles (vide supra).

In short, the emission spectra with gradually increasing concentrations of $\mathrm{Pb}^{2+}$ allow identification of a trend that gauges the cation exchange reaction in the $\mathrm{Zn}(\mathrm{Tb}) \mathrm{S}$ nanoparticles. The potential candidates for the exchange pairs in the system investigated are $\mathrm{Zn}^{2+}: \mathrm{Pb}^{2+}$ and $\mathrm{Tb}^{3+}: \mathrm{Pb}^{2+}$, respectively. The observations presented provide a foundation for photoluminescence based detection of $\mathrm{Pb}^{2+}$ through monitoring the characteristic emission signatures related to $\mathrm{ZnS}$ and $\mathrm{Tb}^{3+}$ in the post-synthetically modified $\mathrm{Zn}(\mathrm{Tb}) \mathrm{S}$ nanoparticles. Moreover, the results obtained in the present work indicate that it is possible to access $\mathrm{PbS}, \mathrm{Pb}(\mathrm{Tb}) \mathrm{S}$, and $\mathrm{Zn}(\mathrm{Tb})(\mathrm{Pb}) \mathrm{S}$ through postsynthetic modification of $\mathrm{Zn}(\mathrm{Tb}) \mathrm{S}$ nanoparticles via the addition of $\mathrm{Pb}^{2+}$ solutions of various concentrations. This enables the tracking of photoluminescence characteristics from low to heavy co-doping and eventually the formation of a material of different chemical identity.

Another important avenue that is related to the cation exchange reaction in semiconductor nanoparticles is the reversibility of the reaction. ${ }^{4}$ In order to evaluate the possibility of such a reverse reaction, experiments have been undertaken in which the $\mathrm{PbS}$ nanoparticles, formed via the treatment of $[\mathrm{Zn}(\mathrm{Tb}) \mathrm{S}]:\left[\mathrm{Pb}^{2+}\right]=1: 1$, were exposed to excess $\mathrm{Zn}^{2+}$ and $\mathrm{Tb}^{3+}$. Visually, the material changes color from brown to off-white suggesting a transformation in the composition of the material. Images of the materials along with the relevant photoluminescence excitation and emission spectra of initial $\mathrm{Zn}(\mathrm{Tb})$ $\mathrm{S}, \mathrm{PbS}$ formed from the treatment of $[\mathrm{Zn}(\mathrm{Tb}) \mathrm{S}]:\left[\mathrm{Pb}^{2+}\right]=1: 1(\mathrm{~A})$, and (A) exposed to excess $\mathrm{Zn}^{2+}$ and $\mathrm{Tb}^{3+}$ precursors are shown in Fig. 8. The $\mathrm{A} / \mathrm{ZnPb}$ sample clearly shows the broad blue and sharp emission of $\mathrm{ZnS}$ and $\mathrm{Tb}^{3+}$, respectively. This suggests that it is indeed possible to attain reversibility in the underlying cation exchange reaction. However, it is worth noting that the broad blue profile is red shifted in the reformed $\mathrm{Zn}(\mathrm{Tb}) \mathrm{S}$ nanoparticles, compared to that in the initial $\mathrm{Zn}(\mathrm{Tb}) \mathrm{S}$ nanoparticles. A difference in surface reconstruction might have a role in this spectral shift. Moreover, a comparison of the emission quantum yield in the initial and reformed $\mathrm{Zn}(\mathrm{Tb}) \mathrm{S}$ nanoparticles reveals a decrease of emission by 1.3 and 3.4 times for the $\mathrm{ZnS}$ and $\mathrm{Tb}^{3+}$ emission, respectively, upon the reverse cation exchange reaction.

To this end, it is worth including the aspects related to cation exchange in semiconductor nanoparticles involving $\mathrm{Zn}(\mathrm{Tb}) \mathrm{S}$ and $\mathrm{Pb}^{2+}$ as the reactant nanoparticles and post-synthetically added cation, respectively. Various previous studies revealed mechanistic insight about this fascinatingly fast reaction in semiconductor nanoparticles. ${ }^{2,4-7}$ Firstly, the exchange process does not affect the anionic network of the nanoparticles significantly, as is evident from the EDS data of the samples investigated. Secondly, as discussed above, based on the electron microscopy measurements we could not detect any faceted characteristics nor could we observe the partial exchange of cations. Thirdly, the efficiency of a cation exchange reaction is dependent on the solubility product constant of metal sulfides and the standard reduction potential of $\mathrm{M}^{n+} / \mathrm{M}$ couples. A lower and higher value of these, respectively, would result in efficient cation exchange. Considering these physical parameters, it is justifiable to explain the cation exchange of component cations of $\mathrm{Zn}(\mathrm{Tb}) \mathrm{S}$ nanoparticles using either $\mathrm{Pb}^{2+}, \mathrm{Hg}^{2+}$ or $\mathrm{Cd}^{2+}$ separately (vide infra). Fourthly, the reversible nature of the exchange reaction could be rationalized using the hard soft acid base (HSAB) theory, especially from the hardness values of a given moiety. For example, the hardness values of $\mathrm{Zn}^{2+}, \mathrm{Tb}^{3+}, \mathrm{Pb}^{2+}$, $\mathrm{C}_{6} \mathrm{H}_{5} \mathrm{OH}$ and $\mathrm{C}_{6} \mathrm{H}_{5} \mathrm{SH}$ are $10.88,14.35,8.46,4.8$ and 4.6, respectively. ${ }^{33}$ In this tabulation, the values for $\mathrm{C}_{6} \mathrm{H}_{5} \mathrm{OH}$ and $\mathrm{C}_{6} \mathrm{H}_{5} \mathrm{SH}$ are included to closely mimic the value for 1-thioglycerol, the value of which was not accessible to us directly. Nonetheless, these values indicate that it would be possible to replace softer $\mathrm{Pb}^{2+}$ from $\mathrm{PbS}$ nanoparticles to reform $\mathrm{Zn}(\mathrm{Tb}) \mathrm{S}$ nanoparticles through reverse cation exchange.

(b) Modification of structural properties. It is worth noting that the EDS measurements (Fig. 5) reveal cation exchange in the nanoparticles with $[\mathrm{Zn}(\mathrm{Tb}) \mathrm{S}]:\left[\mathrm{Pb}^{2+}\right] \geq 1: 1$. However, even with $[\mathrm{Zn}(\mathrm{Tb}) \mathrm{S}]:\left[\mathrm{Pb}^{2+}\right]=1: 10^{-4}$, the broad emission of the $\mathrm{ZnS}$ nanoparticles has decreased intensity, compared to that observed in the $\mathrm{Zn}(\mathrm{Tb}) \mathrm{S}$ nanoparticles. Considering the presence of an appreciable amount of zinc and sulfur in these nanoparticles, the decrease of emission in these cases is not straightforward. It has been anticipated that the decreased blue emission in these cases is likely associated with the $\mathrm{Pb}^{2+}$ induced modifications of the surface properties of the nanoparticles or modulation of photoluminescence properties through the incorporation of $\mathrm{Pb}^{2+}$ in the interstitial sites of the $\mathrm{Zn}(\mathrm{Tb}) \mathrm{S}$ nanoparticles. The results presented here could not differentiate between these possibilities, as this requires detailed structural investigation and is beyond the scope of the current work.

(c) $\mathrm{Tb}^{3+}$ emission enhancement. On a separate note, there is a significant increase of $\mathrm{Tb}^{3+}$ emission at intermediate nominal $\left[\mathrm{Pb}^{2+}\right]$, especially around $[\mathrm{Zn}(\mathrm{Tb}) \mathrm{S}]:\left[\mathrm{Pb}^{2+}\right]=$ $1: 10^{-2}-1: 10^{-3}$. This observation is remarkable in light of a general research topic that aims to brighten the $\mathrm{Ln}^{3+}$ emission in a given system. Making a $\mathrm{Ln}^{3+}$ based luminophore bright enough to be practically useful is a challenging task due to the inefficient direct excitation (associated with the very low molar extinction co-efficient of $\mathrm{Ln}^{3+}$ ) and quenching of luminescence through environmental (ligand and/or solvent) factors. ${ }^{34,35}$ The current work does not identify the origin of the $\mathrm{Tb}^{3+}$ photoluminescence brightening at selected $\mathrm{Pb}^{2+}$ concentrations and this will be addressed in detail in future work. Possibilities might be associated with the structural modification of the nanoparticles at a particular $\left[\mathrm{Pb}^{2+}\right]$, modulation of electronic factors, and tuning of surface properties, among others. 


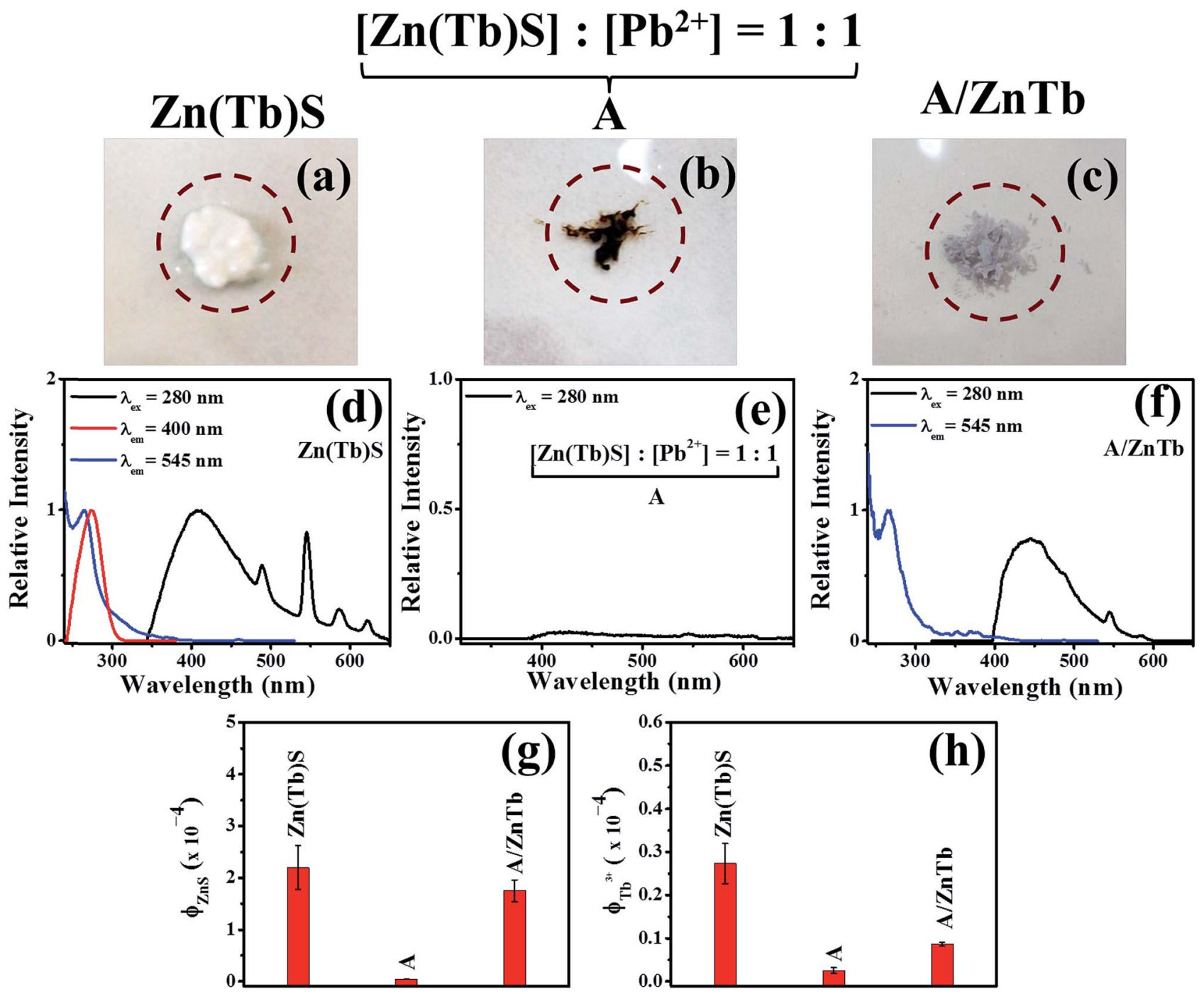

Fig. 8 Images of initial $\mathrm{Zn}(\mathrm{Tb}) \mathrm{S},[\mathrm{Zn}(\mathrm{Tb}) \mathrm{S}]:\left[\mathrm{Pb}^{2+}\right]=1: 1(\mathrm{~A})$, and $\mathrm{A} / \mathrm{ZnTb}$ are shown in panels (a) $-(\mathrm{c})$. The relevant photoluminescence excitation and emission spectra are shown in panels $(\mathrm{d})-(\mathrm{f})$, with the trends in emission quantum yields shown in panels $(\mathrm{g})$ and $(\mathrm{h})$.

\section{Host dependent $\mathbf{T b}^{3+}$ emission sensitization}

At this juncture, it is worth comparing the efficiency of ZnS and $\mathrm{PbS}$ as the core of the nanoparticles in sensitizing the $\mathrm{Tb}^{3+}$ emission. Host sensitization is a useful way to realize lanthanide emission and is a requirement due to the extremely low molar extinction co-efficient and environment induced luminescence quenching effects. ${ }^{34,35}$ We have been interpreting the luminescence sensitization of dopant moieties in semiconductor nanoparticles using a photophysical model in which the dopants act as a charge (electron and/or hole) traps in the host matrix and the exciton recombination at these trap sites populates the dopant luminescent energy levels, thereby generating host sensitized dopant emission from the composite host (semiconductor nanoparticles) $-\mathrm{Ln}^{3+}$ (guest) assembly. ${ }^{22,30-32,36,37}$

In such a photophysical rationalization, it is important to identify the relative position of the $\mathrm{Ln}^{3+}$ ground and luminescent energy levels with respect to the valence and conduction bands of the host material. It has generally been observed that appreciable host sensitized $\mathrm{Ln}^{3+}$ emission could be realizable when the $\mathrm{Ln}^{3+}$ ground and luminescent energy levels are placed optimally above and below the valence and conduction bands of the host material. To construct such energy level schematics, we adopted the method proposed by Dorenbos and co-workers, ${ }^{38,39}$ in which the $\mathrm{Ln}^{3+}$ binding energy trend has been considered to be universal due to the core like features and the charge transfer energy between the anion valence band and $\mathrm{Eu}^{3+}$ ground state has been considered to be same as the energy difference between the valence band of the host material and the $\mathrm{Eu}^{2+}$ ground state. Moreover, by placing the $\mathrm{Eu}^{3+}$ ground state energy level at $5.7 \mathrm{eV}$ lower than the $\mathrm{Eu}^{2+}$ ground state for lower band gap materials, like the materials investigated in the present work, and considering the universal relative binding energy trend of $\mathrm{Ln}^{3+}$, the entire relative energy level schematic can be constructed.

The relative energy level positions of the $\mathrm{Tb}^{3+}$ ground and luminescent energy levels with respect to the valence and conduction bands of the $\mathrm{ZnS}$ and PbS hosts are shown in Fig. 9. This schematic clearly identifies that while both the hosts are 


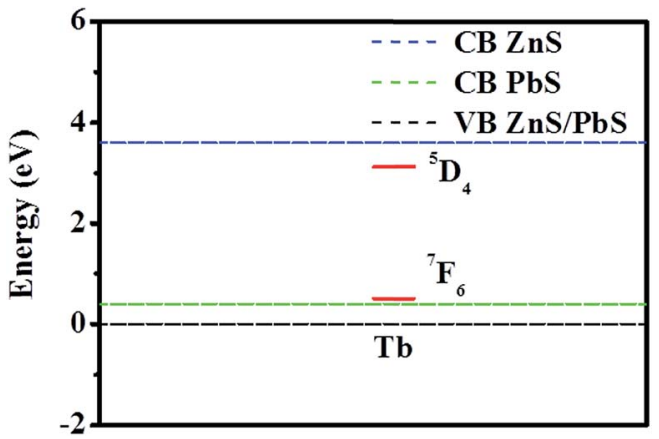

Fig. 9 Relative energy level positions of the $\mathrm{Tb}^{3+}$ ground and luminescent energy levels are shown with respect to the valence and conduction bands of the host materials. In constructing the energy level schematic, the bulk band gap values of the respective materials have been considered.

efficient in hole trapping at the $\mathrm{Tb}^{3+}$ ground energy level, the autoionization is expected to be very efficient in $\mathrm{PbS}$ and the same would be negligible in $\mathrm{ZnS}$. Thus for sensitization of $\mathrm{Tb}^{3+}$ emission, ZnS would act as better host material, compared to that which could be realized from PbS based materials.

\section{Photoluminescence spectra with post-synthetic modification using other cations}

With the advent of tuning the emission of $\mathrm{ZnS}$ and $\mathrm{Tb}^{3+}$ separately in the $\mathrm{Zn}(\mathrm{Tb}) \mathrm{S} / \mathrm{Pb}$ nanoparticles, we studied the effects when other cations $\left(\mathrm{M}^{n+}\right)$ were added post-synthetically to the $\mathrm{Zn}(\mathrm{Tb}) \mathrm{S}$ nanoparticles. For this study, $\mathrm{Hg}^{2+}, \mathrm{Cd}^{2+}, \mathrm{Ca}^{2+}, \mathrm{Mg}^{2+}$, $\mathrm{Na}^{+}$and $\mathrm{K}^{+}$were considered, with a nominal $[\mathrm{Zn}(\mathrm{Tb}) \mathrm{S}]:\left[\mathrm{M}^{n+}\right]$ maintained at a $1: 1$ and $1: 10^{-2}$ ratio. The choice of these concentration ratios was based on the corresponding $\mathrm{Pb}^{2+}$ case, with the exchange of both $\mathrm{Zn}^{2+}$ and $\mathrm{Tb}^{3+}$, and a representative case where $\mathrm{Tb}^{3+}$ emission enhancement was observed, respectively.

The trends in the broad and sharp emission of the ZnS nanoparticles and $\mathrm{Tb}^{3+}$, respectively, from these measurements with $[\mathrm{Zn}(\mathrm{Tb}) \mathrm{S}]:\left[\mathrm{M}^{n+}\right]=1: 1$ are summarized in Fig. 10, with the corresponding photoluminescence spectral profiles shown in Fig. S2-S4 (ESI $\dagger)$. For $[\mathrm{Zn}(\mathrm{Tb}) \mathrm{S}]:\left[\mathrm{M}^{n+}\right]=1: 1$, the data reveal a disappearance of both $\mathrm{ZnS}$ and $\mathrm{Tb}^{3+}$ emission characteristics in the $\mathrm{Zn}(\mathrm{Tb}) \mathrm{S}$ nanoparticles with post-synthetic modification of the nanoparticles using $\mathrm{Hg}^{2+}$. This observation is at least similar to the corresponding case with $\mathrm{Pb}^{2+}$ (vide supra). The extent of such a disappearance is less evident with the addition of $\mathrm{Cd}^{2+}$, showing a red shift in the emission spectral profile. This shift is most likely associated with the formation of a mixed phase in the nanoparticles, generating a contribution from lower band gap materials. Similar experiments with the addition of $\mathrm{Ca}^{2+}, \mathrm{Mg}^{2+}, \mathrm{Na}^{+}$and $\mathrm{K}^{+}$did not produce similar dramatic decreases in the luminescence of the $\mathrm{Zn}(\mathrm{Tb}) \mathrm{S}$ nanoparticles. In these cases, a marginal to significantly distinct decrease in the broad emission of the $\mathrm{ZnS}$ nanoparticles is noticeable with a consistent blue shift in the broad blue spectral band, which has been attributed to the subtle changes in the structure of the nanoparticles. These observations collectively indicate that it is indeed possible to detect heavy metals $\left(\mathrm{Pb}^{2+}\right.$, $\mathrm{Hg}^{2+}$, and $\mathrm{Cd}^{2+}$ ) selectively using the post-synthetic modification of $\mathrm{Zn}(\mathrm{Tb}) \mathrm{S}$ nanoparticles. The nanoparticles where the metal ion is $\mathrm{Ca}^{2+}, \mathrm{Mg}^{2+}, \mathrm{Na}^{+}$and $\mathrm{K}^{+}$cause a change in the intensity of the sharp $\mathrm{Tb}^{3+}$ emission, compared to that observed in the $\mathrm{Zn}(\mathrm{Tb}) \mathrm{S}$ nanoparticles. An emission enhancement of $\mathrm{Tb}^{3+}$ in cases of post-synthetic modification with either $\mathrm{Mg}^{2+}$ or $\mathrm{Na}^{+}$ is noticeable, where an increase of emission by 1.1 and 1.3 times has been observed, respectively.

On the other hand, $[\mathrm{Zn}(\mathrm{Tb}) \mathrm{S}]:\left[\mathrm{M}^{n+}\right]=1: 10^{-2}$ reveals a specific nature that is associated with $\mathrm{Pb}^{2+}$ among the cations investigated. These results are summarized in Fig. 11 and the corresponding spectra are shown in Fig. S5-S7 (ESI $\dagger$ ). The reason behind this sort of specificity, while being unknown at this juncture, could be associated with the similar ionic radii of $\mathrm{Tb}^{3+}$ and $\mathrm{Pb}^{2+}$, being 118 and $119 \mathrm{pm}$, respectively. This reasoning awaits further detailed study and will be addressed independently. Moreover, for the cases with $\mathrm{Ca}^{2+}, \mathrm{Mg}^{2+}, \mathrm{Na}^{+}$and $\mathrm{K}^{+}$, the broad $\mathrm{ZnS}$ emission decreases significantly with a blue shift in the blue emission band, suggesting that even a small amount of post-synthetically added cations tune the photophysical properties associated with the surface related emission in the $\mathrm{Zn}(\mathrm{Tb}) \mathrm{S}$ nanoparticles significantly. The emission enhancement in the cases with post-synthetic addition of either $\mathrm{Mg}^{2+}$ or $\mathrm{Na}^{+}$is, however, not apparent.

To summarize, it is evident that control of the broad and sharp emission of $\mathrm{ZnS}$ and $\mathrm{Tb}^{3+}$, respectively, in the post-
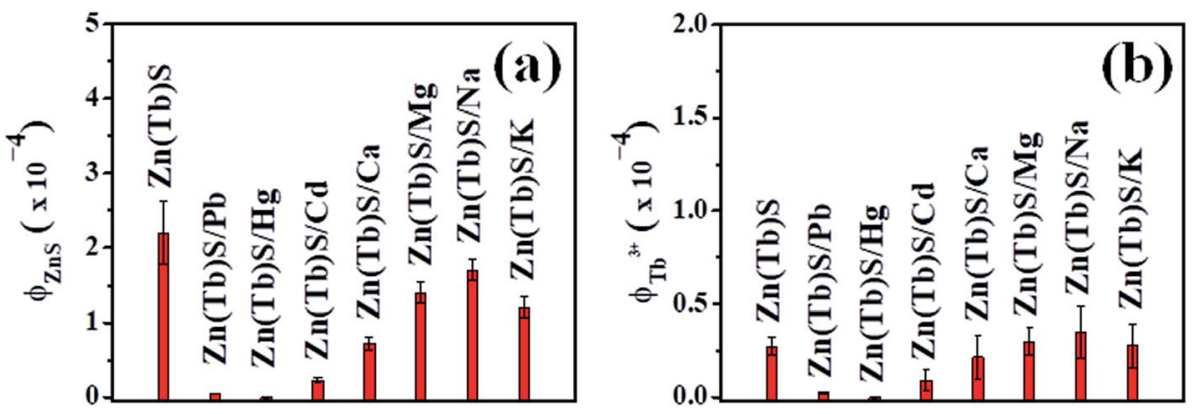

Fig. 10 The trend in the broad and sharp emission of the ZnS nanoparticles (panel a) and $\mathrm{Tb}^{3+}$ (panel b), respectively, are shown for cases where the $\mathrm{Zn}(\mathrm{Tb}) \mathrm{S}$ nanoparticles were post-synthetically treated with $\mathrm{M}^{n+}$, with $[\mathrm{Zn}(\mathrm{Tb}) \mathrm{S}]:\left[\mathrm{M}^{n+}\right]=1: 1$. The values reported are average and standard deviation from two independent measurements. 

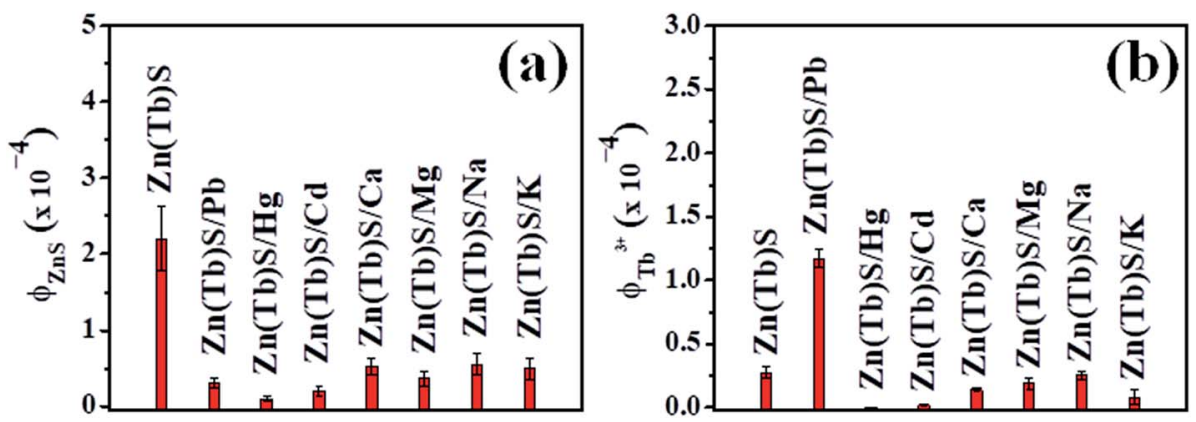

Fig. 11 The trend in the broad and sharp emission of the ZnS nanoparticles (panel a) and $\mathrm{Tb}^{3+}$ (panel b), respectively, are shown for cases where the $\mathrm{Zn}(\mathrm{Tb}) \mathrm{S}$ nanoparticles were post-synthetically treated with $\mathrm{M}^{n+}$, with $[\mathrm{Zn}(\mathrm{Tb}) \mathrm{S}]:\left[\mathrm{M}^{n+}\right]=1: 10^{-2}$. The values reported are average and standard deviation from two independent measurements.

synthetically modified $\mathrm{Zn}(\mathrm{Tb}) \mathrm{S}$ nanoparticles is possible through varying the relative concentrations of reactants, with a dependence on the identity of the post-synthetically added cation. A comparative summary of the emission trend for the nanoparticles investigated in this work is provided in Table 1, clearly indicating that it is indeed possible to obtain a wide range of emission properties through simple chemical treatment of semiconductor nanoparticles under ambient conditions.

Overall, it has been argued that varying the ratio of $\mathrm{Zn}(\mathrm{Tb}) \mathrm{S}$ nanoparticles and $\mathrm{Pb}^{2+}$ in a range of six orders allows access to scenarios ranging from low to heavy doping levels and ultimately the synthesis of a material of a different chemical identity. Moreover, the enhancement of $\mathrm{Tb}^{3+}$ emission has been found to be $\mathrm{Pb}^{2+}$ specific in the range $[\mathrm{Zn}(\mathrm{Tb}) \mathrm{S}]:\left[\mathrm{M}^{n+}\right]=$ $1: 10^{-2}-1: 10^{-3}$; this led us to envisage the possibility that there exist subtle structural variations that correlate with the similar ionic radii of $\mathrm{Tb}^{3+}$ and $\mathrm{Pb}^{2+}$. With an equimolar or higher ratio for the concentration of the $\mathrm{Zn}(\mathrm{Tb}) \mathrm{S}$ nanoparticles and $\mathrm{Pb}^{2+}$, cation exchange plays a dominant role. This necessarily leads to the (i) decrease in the amount of $\mathrm{Tb}^{3+}$ due to the exchange of cations and (ii) lesser sensitization ability of $\mathrm{PbS}$ to generate the $\mathrm{Tb}^{3+}$ emission; both supporting a decrease of $\mathrm{Tb}^{3+}$ emission. It is important to note that realization of appreciable $\mathrm{Tb}^{3+}$ emission requires host sensitization due to its very low molar extinction co-efficient and the efficient environment induced quenching of $\mathrm{Tb}^{3+}$ luminescence. ${ }^{34,35}$ While these aspects satisfactorily identify the reason for $\mathrm{Tb}^{3+}$ emission

Table 1 A comparative summary of emission properties in the post-synthetically modified nanoparticles studied

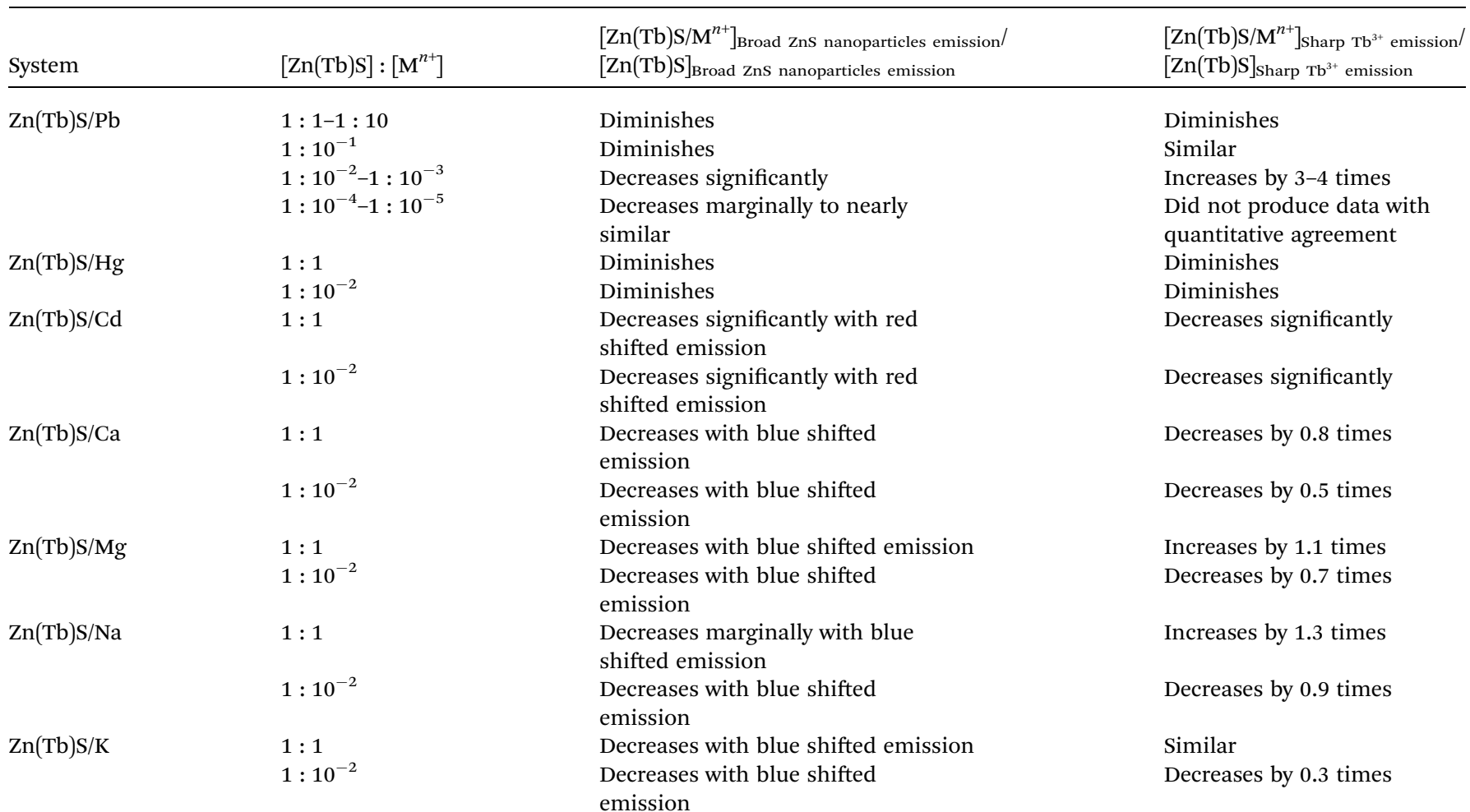


decrease in the domain of cation exchange, the specific reason for $\mathrm{Tb}^{3+}$ emission enhancement at particular relative concentrations of $\mathrm{Pb}^{2+}$ is still not clearly identified. To this end, we wish to undertake a detailed time-resolved photoluminescence investigation of both the broad $\mathrm{ZnS}$ and sharp $\mathrm{Tb}^{3+}$ emissions, respectively, as a function of $\mathrm{Pb}^{2+}$ concentration to reveal the nature of the radiative and non-radiative rates in these systems. We, however, believe that such a study is beyond the scope of the current work, which mainly attempts to explore how the photophysical properties of the $\mathrm{Zn}(\mathrm{Tb}) \mathrm{S}$ nanoparticles change as a function of post-synthetically added $\mathrm{Pb}^{2+}$ and in cases with selected concentrations of other cations.

\section{Detection of metal ions}

Heavy metals are hazardous and due to their nonbiodegradability they accumulate in the environment and pose alarming health related issues resulting from food and water contamination. Efforts have been devoted to detecting and possibly removing these cations to develop systems within the acceptable concentration limits. Sensors based on colorimetry and photoluminescence are attractive due to the extremely high sensitivity of these optical measurements as well their easy accessibility in routine chemistry laboratories. Related efforts towards the development of heavy metal sensors vary widely in chemical nature, from small molecules to supramolecular assemblies. ${ }^{40}$ Although these developed systems are based on a wide range of otherwise uncorrelated mechanisms (aggregation induced, photoinduced electron transfer, and resonance energy transfer, among others), demonstrating the usefulness of the post-synthetic modification of semiconductor nanoparticles towards this goal is not widespread. This reaction strategy offers an easy and cost effective chemical treatment that can be performed with a single batch of nanoparticles, eventually reducing human effort and time associated with multiple syntheses.

The use of cation exchange reactions to develop sensors for heavy metal ions and lead in particular has been attempted by few research groups. ${ }^{25,26}$ For example, Brock and co-workers developed ${\mathrm{a} \mathrm{Pb}^{2+}}^{2+}$ and $\mathrm{Hg}^{2+}$ sensor that is based on a cation exchange reaction from zinc sulfide nanoparticles and they quantified the process using inductively coupled plasma mass spectroscopy (ICP-MS). ${ }^{25}$ Chattopadhyay and co-workers demonstrated cation exchange reactions of $\mathrm{Hg}^{2+}, \mathrm{Ag}^{+}$and $\mathrm{Pb}^{2+}$ from chitosan stabilized ZnS quantum dots towards the development of sensors of these cations and estimated a detection limit for $\mathrm{Hg}^{2+}$ that is in the range of $\mathrm{ppm} .{ }^{26}$ Based on the demanding experimental procedure for ICP based measurements and the relatively easier realization of photoluminescence experiments with high sensitivity from the perspective of both instrumentation and feasibility of performing measurements in vivo, our aim was to develop a photoluminescence based sensor for biologically hazardous metal ions through the post-synthetic modification of inorganic nanoparticles. This approach collectively offers easy realization of both the chemical reaction and the measurement. Moreover, while most of the previous studies carried out the exchange reaction using undoped nanoparticles, we have attempted to perform such a reaction in the presence of two cations. The terbium cation incorporated zinc sulfide [ $\mathrm{Zn}(\mathrm{Tb}) \mathrm{S}]$ nanoparticles were considered for this purpose, with the nanoparticles being treated with an appropriate metal nitrate salt post-synthetically. The strategy of performing the exchange reaction in the presence of two cations of diverse chemical nature provides a route to use the robustness of the cation exchange reaction in semiconductor nanoparticles. Additionally, the involvement of lanthanide cations (terbium in the present study) offers the possibility of time-gated measurements, a feature related to the longer (microseconds to milliseconds) photoluminescence lifetime of these cations. Moreover, in a given scenario with the occurrence of simultaneous cation exchange reactions, the experimental outcome also cross verifies the detection results.

The trend in the relative emission of the broad $\mathrm{ZnS}$ and sharp $\mathrm{Tb}^{3+}$ in the post-synthetically modified $\mathrm{Zn}(\mathrm{Tb}) \mathrm{S}$ nanoparticles as a function of $\left[\mathrm{Pb}^{2+}\right]$ is shown in Fig. 12. The results presented indicate that based on a decrease of the broad emission of $\mathrm{ZnS}$, it is possible to detect $\mathrm{Pb}^{2+}$ through monitoring the photoluminescence properties related to $\mathrm{ZnS}$ in the $\mathrm{Zn}(\mathrm{Tb}) \mathrm{S}$ nanoparticles, with a minimum concentration ratio of $[\mathrm{Zn}(\mathrm{Tb}) \mathrm{S}]:\left[\mathrm{Pb}^{2+}\right]=1: 10^{-4}$. Moreover, the feature of a $\mathrm{Pb}^{2+}$ induced increase in the $\mathrm{Tb}^{3+}$ emission could also be utilized to detect $\mathrm{Pb}^{2+}$ with a minimum concentration ratio of $[\mathrm{Zn}(\mathrm{Tb})$ $\mathrm{S}]:\left[\mathrm{Pb}^{2+}\right]=1: 10^{-3}$. A $[\mathrm{Zn}(\mathrm{Tb}) \mathrm{S}]$ of $0.3 \mathrm{mM}$ was used in the present work for the electronic spectroscopy experiments. Correspondingly, the $\mathrm{Tb}^{3+}$ concentration was around $30 \mu \mathrm{M}$, considering the dopant ratio during the synthesis of the $\mathrm{Zn}(\mathrm{Tb})$ $S$ nanoparticles and assuming complete incorporation of the dopants during the synthesis of the nanoparticles. Additionally, we note that a nanoparticle concentration in the order of tens of millimolar was required for the purification of the postsynthetically modified nanoparticles. Based on this, a $\mathrm{Pb}^{2+}$ detection capability of $\sim 0.2$ ppm was estimated using the broad ZnS and sharp $\mathrm{Tb}^{3+}$ related emission characteristics separately in the post-synthetically modified $\mathrm{Zn}(\mathrm{Tb}) \mathrm{S}$ nanoparticles.

Moreover, the data in Fig. 12 clearly indicate a deviation from linear behavior. It is important to note that the nanoparticles in the present work have been modified using $\mathrm{Pb}^{2+}$ concentrations that vary by $10^{6}$ in the order of magnitude and the discussion above discusses the different physical processes associated with the different concentration regimes. For example, for the broad $\mathrm{ZnS}$ emission, $[\mathrm{Zn}(\mathrm{Tb}) \mathrm{S}]:\left[\mathrm{Pb}^{2+}\right]<1: 1$ will have a contribution from the structural modification of the nanoparticles, in the same way $>1: 1$ measures cation exchange. For the sharp $\mathrm{Tb}^{3+}$ emission, $[\mathrm{Zn}(\mathrm{Tb}) \mathrm{S}]:\left[\mathrm{Pb}^{2+}\right]=$ $1: 10^{-2}-1: 10^{-3}$ and $>1: 1$ enable monitoring of the $\mathrm{Tb}^{3+}$ emission enhancement and cation exchange, respectively. Accordingly, it is anticipated that a deviation from linearity is not surprising.

At this juncture we note that while the use of $\mathrm{Zn}(\mathrm{Tb}) \mathrm{S}$ nanoparticles for the detection of $\mathrm{Pb}^{2+}$ in aqueous dispersions is not applicable to access the regulatory amount of $<15 \mathrm{ppb}$ set by the US Environmental Protection Authority (EPA), ${ }^{\mathbf{4 0}}$ they would only be used for heavily contaminated samples. This 

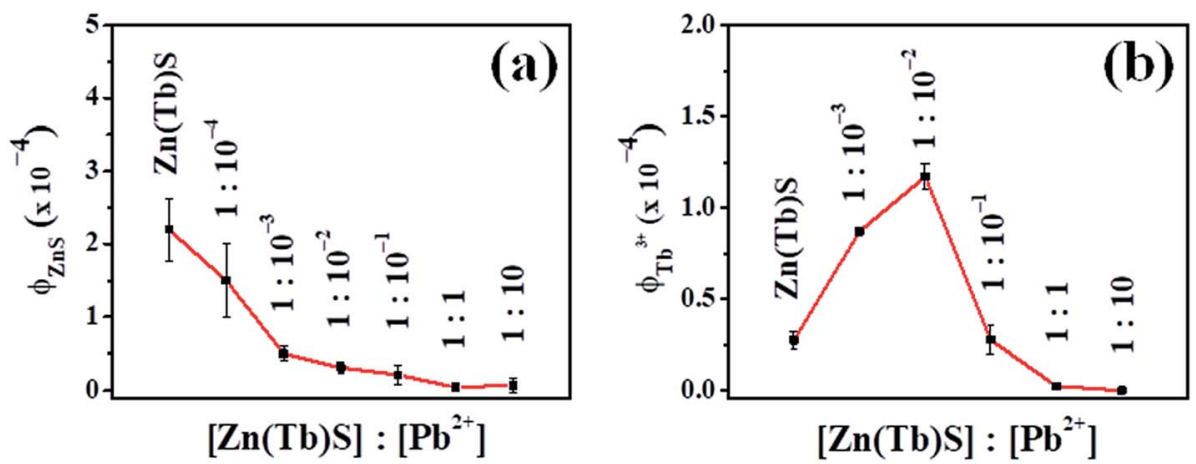

Fig. 12 The relative emission of the broad $\mathrm{ZnS}$ and sharp $\mathrm{Tb}^{3+}$ in the post-synthetically modified $\mathrm{Zn}(\mathrm{Tb}) \mathrm{S}$ nanoparticles as a function of $\left[\mathrm{Pb}^{2+}\right]$ is shown. The lines on the curves are a visual representation indicating the deviation from linearity.

difficulty is associated with the relatively low molar extinction co-efficient of the $\mathrm{ZnS}$ nanoparticles, being in the range of $10^{3} \mathrm{M}^{-1} \mathrm{~cm}^{-1}$. Nonetheless, the results presented in this work clearly show the vastness of the photoluminescence properties that evolve as a function of reactant concentration and direct the use of these properties for similar metal ion detection using other semiconductor nanoparticles with higher molar extinction co-efficients. However, an associated challenge remains in choosing a suitable host (semiconductor nanoparticles)-guest $\left(\mathrm{Ln}^{3+}\right)$ combination, ${ }^{36}$ with appreciable host sensitized $\mathrm{Ln}^{3+}$ emission. Optimizing such a nanoparticle system for use in detecting even lower levels of $\mathrm{Pb}^{2+}$ is currently underway in our laboratory.

\section{Conclusions}

Motivated by the simple chemical procedure of post-synthetic modification of semiconductor nanoparticles under ambient conditions, and the high sensitivity and easy accessibility of photoluminescence measurements, this study aims to address the possibilities of controlling the emission in postsynthetically modified terbium incorporated zinc sulfide nanoparticles. A remarkable dependence of the emission properties has been observed, which is guided by the relative reactant concentration and identity of the post-synthetically added cation. Cation exchange, structural modifications without necessarily exchanging the cations, and emission enhancement of dopants have been found to interplay in the outcome for the post-synthetically modified $\mathrm{Zn}(\mathrm{Tb}) \mathrm{S}$ nanoparticles. In the $\mathrm{Zn}(\mathrm{Tb}) \mathrm{S} / \mathrm{Pb}$ nanoparticles, a concentration dependence for the cation exchange has been observed, with $[\mathrm{Zn}(\mathrm{Tb}) \mathrm{S}]:\left[\mathrm{Pb}^{2+}\right] \geq 1: 1$ displacing both $\mathrm{Zn}^{2+}$ and $\mathrm{Tb}^{3+}$ from the $\mathrm{Zn}(\mathrm{Tb}) \mathrm{S}$ nanoparticles. The disappearance and emission enhancement of the broad $\mathrm{ZnS}$ related and sharp $\mathrm{Tb}^{3+}$ emission characteristics, respectively, provide an opportunity to detect $\mathrm{Pb}^{2+}$ with at least $[\mathrm{Zn}(\mathrm{Tb}) \mathrm{S}]:\left[\mathrm{Pb}^{2+}\right]=1: 10^{-4}$ and $1: 10^{-3}$, respectively. In all the cases with $\mathrm{Tb}^{3+}$ emission evident, the nanoparticles were acting as an optical antenna to sensitize the $\mathrm{Tb}^{3+}$ emission. Performing similar experiments with other cations indicates the importance of the identity of the postsynthetically added cation and enables the detection of $\mathrm{Hg}^{2+}$ that is comparable to or better than that of $\mathrm{Pb}^{2+}$, with lesser detection efficiency for $\mathrm{Cd}^{2+}$. The corresponding cases with $\mathrm{Ca}^{2+}, \mathrm{Mg}^{2+}, \mathrm{Na}^{+}$, and $\mathrm{K}^{+}$did not produce a similar decrease in the $\mathrm{Zn}(\mathrm{Tb}) \mathrm{S}$ nanoparticles emission characteristics, suggesting using the cation exchange strategy to sense heavy metals in general. However, the post-synthetically added $\mathrm{Pb}^{2+}$ induced $\mathrm{Tb}^{3+}$ emission enhancement has been found to be specific in nature, at least among the cations investigated. However, cations like $\mathrm{Mg}^{2+}$ and $\mathrm{Na}^{+}$when post-synthetically added have been found to enhance the $\mathrm{Tb}^{3+}$ emission in the $\mathrm{Zn}(\mathrm{Tb}) \mathrm{S}$ nanoparticles. This feature is attractive to a general research area that is associated with increasing lanthanide cation emission, a challenging task related to the extremely low molar extinction co-efficients of these cations. From the acquired spectra, the detection capability for $\mathrm{Pb}^{2+}$ has been estimated as $\sim 0.2$ ppm using either the broad or sharp emission of $\mathrm{ZnS}$ and $\mathrm{Tb}^{3+}$, respectively, in the post-synthetically modified $\mathrm{Zn}(\mathrm{Tb}) \mathrm{S}$ nanoparticles. The associated physical processes are guided by the structural modifications and $\mathrm{Tb}^{3+}$ emission enhancement in the $\mathrm{Zn}(\mathrm{Tb}) \mathrm{S}$ nanoparticles, respectively. Finally, the use of trivalent lanthanide cations $\left(\mathrm{Tb}^{3+}\right.$ in the present work) ensures the accessibility of time-gated measurements that are associated with longer (microseconds to milliseconds) luminescence lifetimes, further increasing the detection sensitivity using the lanthanide luminescence. Collectively, the data obtained in the present work provide a foundation to use the emission characteristics of post-synthetically modified semiconductor nanoparticles to detect heavy metal cations in general and lead in particular in aqueous dispersions using the wide range of photoluminescence characteristics accessible through varying the relative concentrations of the reactants and the identity of the post-synthetically added cation.

\section{Conflicts of interest}

There are no conflicts of interest to declare.

\section{Acknowledgements}

Financial assistance from the University Grants Commission (UGC) (F. 20-11(17)/2013(BSR)), Science and Engineering Research Board (SERB), Department of Science and Technology (DST) (SB/S1/PC-040/2013) is gratefully acknowledged. Ms Saoni 
Rudra and Mr Gouranga H. Debnath acknowledge the University of Calcutta for supporting fellowships. The authors thank Dr Aritra Banerjee and Mr Subarna Das, Department of Physics, University of Calcutta for the XRD measurements using the diffractometer (Model: X'Pert Powder, Make-PANalytical) procured under DST-PURSE program. The authors also thank Ms Urmila Goswami, Mr Mrinal Kanti Garai and Mr Prothyush Sengupta for helping us with the electron microscopy measurements.

\section{References}

1 J. Zhang, Q. Di, J. Liu, B. Bai, J. Liu, M. Xu and J. Liu, J. Phys. Chem. Lett., 2017, 8, 4943-4953.

2 B. J. Beberwyck, Y. Surendranath and A. P. Alivisatos, J. Phys. Chem. C, 2013, 117, 19759-19770.

3 J. B. Rivest and P. K. Jain, Chem. Soc. Rev., 2013, 42, 89-96. 4 D. H. Son, S. M. Hughes, Y. Yin and A. P. Alivisatos, Science, 2004, 306, 1009-1012.

5 R. D. Robinson, B. Sadtler, D. O. Demchenko, C. K. Erdonmez, L.-W. Wang and A. P. Alivisatos, Science, 2007, 317, 355-358.

6 B. Sadtler, D. O. Demchenko, H. Zheng, S. M. Hughes, M. G. Merkle, U. Dahmen, L.-W. Wang and A. P. Alivisatos, J. Am. Chem. Soc., 2009, 131, 5285-5293.

7 P. K. Jain, L. Amirav, S. Aloni and A. P. Alivisatos, J. Am. Chem. Soc., 2010, 132, 9997-9999.

8 B. J. Beberwyck and A. P. Alivisatos, J. Am. Chem. Soc., 2012, 134, 19977-19980.

9 K. Miszta, D. Dorfs, A. Genovese, M. R. Kim and L. Manna, ACS Nano, 2011, 5, 7176-7183.

10 H. Li, M. Zanella, A. Genovese, M. Povia, A. Falqui, C. Giannini and L. Manna, Nano Lett., 2011, 11, 4964-4970.

11 H. Li, R. Brescia, M. Povia, M. Prato, G. Bertoni, L. Manna and I. Moreels, J. Am. Chem. Soc., 2013, 135, 12270-12278.

12 L. D. Trizio, H. Li, A. Casu, A. Genovese, A. Sathya, G. C. Messina and L. Manna, J. Am. Chem. Soc., 2014, 136, 16277-16284.

13 D. Mocatta, G. Cohen, J. Schattner, O. Millo, E. Rabani and U. Banin, Science, 2011, 332, 77-81.

14 C. Dong and F. C. J. M. van Veggel, ACS Nano, 2009, 3, 123130.

15 K. Sooklal, B. S. Cullum, S. M. Angel and C. J. Murphy, J. Phys. Chem., 1996, 100, 4551-4555.

16 A. V. Isarov and J. Chrysochoos, Langmuir, 1997, 13, 31423149.

17 A. W. Wills, M. S. Kang, K. M. Wentz, S. E. Hayes, A. Sahu, W. L. Gladfelter and D. J. Norris, J. Mater. Chem., 2012, 22, 6335-6342.
18 A. Sahu, M. S. Kang, A. Kompch, C. Notthoff, A. W. Wills, D. Deng, M. Winterer, C. D. Frisbie and D. J. Norris, Nano Lett. , 2012, 12, 2587-2594.

19 A. J. Almeida, A. Sahu, A. Riedinger, D. J. Norris, M. S. Brandt, M. Stutzmann and R. N. Pereira, J. Phys. Chem. C, 2016, 120, 13763-13770.

20 P. Mukherjee, R. F. Sloan, C. M. Shade, D. H. Waldeck and S. Petoud, J. Phys. Chem. C, 2013, 117, 14451-14460.

21 J. Nanda, S. Sapra, D. D. Sarma, N. Chandrasekharan and G. Hodes, Chem. Mater., 2000, 12, 1018-1024.

22 A. Chakraborty, G. H. Debnath, M. Ahir, S. Bhattacharya, P. Upadhyay, A. Adhikary and P. Mukherjee, RSC Adv., 2016, 6, 43304-43315.

23 P. Calandra, M. Goffredi and V. T. Liveri, Colloids Surf., A, 1999, 160, 9-13.

24 J. E. Lewis and M. Maroncelli, Chem. Phys. Lett., 1998, 282, 197-203.

25 I. R. Pala and S. L. Brock, ACS Appl. Mater. Interfaces, 2012, 4, 2160-2167.

26 A. Jaiswal, S. S. Ghosh and A. Chattopadhyay, Langmuir, 2012, 28, 15687-15696.

27 W. Luo, R. Li, G. Liu, M. R. Antonio and X. Chen, J. Phys. Chem. C, 2008, 112, 10370-10377.

28 W. G. Becker and A. J. Bard, J. Phys. Chem., 1983, 87, 48884893.

29 D. E. Dunstan, A. Hagfeldt, M. Almgren, H. O. G. Siegbahn and E. Mukhtar, J. Phys. Chem., 1990, 94, 6197-6804.

30 P. Mukherjee, C. M. Shade, A. M. Yingling, D. N. Lamont, D. H. Waldeck and S. Petoud, J. Phys. Chem. A, 2011, 115, 4031-4041.

31 G. H. Debnath, A. Chakraborty, A. Ghatak, M. Mandal and P. Mukherjee, J. Phys. Chem. C, 2015, 119, 24132-24141.

32 G. H. Debnath, A. Chakraborty and P. Mukherjee, RSC Adv., 2016, 6, 85230-85241.

33 R. G. Pearson, Inorg. Chem., 1988, 27, 734-740.

34 J.-C. G. Bünzli, Chem. Rev., 2010, 110, 2729-2755.

35 A. Beeby, I. M. Clarkson, R. S. Dickins, S. Faulkner, D. Parker, L. Royle, A. S. de Sousa, J. A. G. Williams and M. Woods, J. Chem. Soc., Perkin Trans. 2, 1999, 493-503.

36 A. Chakraborty, G. H. Debnath, N. R. Saha, D. Chattopadhyay, D. H. Waldeck and P. Mukherjee, J. Phys. Chem. C, 2016, 120, 23870-23882.

37 P. Manna, A. Chakraborty, G. H. Debnath and P. Mukherjee, J. Phys. Chem. Lett., 2017, 8, 2794-2798.

38 P. Dorenbos and E. van der Kolk, Appl. Phys. Lett., 2006, 89, 061122.

39 P. Dorenbos, J. Alloys Compd., 2009, 488, 568-573.

40 H. N. Kim, W. X. Ren, J. S. Kim and J. Yoon, Chem. Soc. Rev., 2012, 41, 3210-3244. 